\title{
Construct Validity of the Revised Collett-Lester Fear of Death and Dying Scale
}

\author{
by \\ Deborah Claire Mooney RN, CCN, BaHlthSc (Nrs), Grad \\ Dip Adv. Nrs Stud (Dist)
}

Being a thesis submitted in partial fulfillment of the requirements for the Degree of Master of Philosophy - Griffith University 
I hereby declare that this submission is my own work and that, to the best of my knowledge and belief, it contains no material previously published or written by another person nor material to which a substantial extent has been accepted for the award of any other Diploma or Degree of a University or other institute of higher learning, except where due acknowledgement is made within the text.

Deborah Claire Mooney 
I dedicate this thesis to my mentor, colleague and friend, Professor John O'Gorman, for his patience, guidance and scholarship. 


\begin{abstract}
This thesis examined the construct validity of the Revised Collett-Lester Fear of Death and Dying Scale in three separate studies.
\end{abstract}

Study $1(n=106)$ examined the relationship between the Collett-Lester subscales and the subscales of the Multidimensional Fear of Death and Dying Scale as well as measures of extraversion, neuroticism, and social desirability. Test-retest reliability over a 6 -week period was found to be .82 and internal consistency values for the four subscales ranged from .77 to .86 . A correlation was demonstrated between the Fear of Death and Dying Scale and the Multidimensional Fear of Death Scale. Neuroticism was found to relate to Death and Dying of others subscales, while extraversion, social desirability and gender were found to be unrelated to any of the four subscales. Study $2(n=87)$ examined the sensitivity of the scale to an intervention designed to change attitudes to death and dying. Changes in attitudes were noted to be statistically significant with the experimental group following a six-week time frame. However, marginal increases in scores for the comparison group was also noted and replication of certain aspects of this study is advised. The third and final study examined the factor structure of the scale. Two sample sizes were used, 106 and 493. The data were subjected to principal component factor analysis using varimax and orthogonal rotational procedures. The results provided some support for two of the subscales.

It is concluded that despite some psychometric weaknesses the Revised Collett-Lester Fear of Death and Dying Scale is a suitable instrument with which to measure death anxiety. 


\section{Chapter 1}

The Measurement of Death Anxiety

Methods of Measuring Death Anxiety 3

Construct Validity $\quad 5$

$\begin{array}{ll}\text { A Review of Existing Scales } & 7\end{array}$

The Lester Attitude Towards Death Scale $\quad 7$

The Boyar Fear of Death Scale 9

The Templer Death Anxiety Scale 10

The Revised Death Anxiety Scale 13

The Death Concern Scale 14

Bugen's Coping With Death Scale 15

The Threat Index 16

The Multidimensional Death Anxiety Scale 18

The Three Death Anxiety Factor Scale 19

The Fear of Personal Death Scale 20

The Multidimensional Fear of Death Scale 21

The Original Collett-Lester Fear of Death and Dying Scale 24

The Revised Collett-Lester Fear of Death and Dying Scale 31

The Rationale for the Present Series of Studies 35

\section{Chapter 2}

Study 1- Reliability and Validity of the Revised Collett-

Lester Fear of Death and Dying Scale

Introduction 38

Method 41

$\begin{array}{ll}\text { Participants } & 41\end{array}$

Materials $\quad 42$

$\begin{array}{ll}\text { Procedure } & 42\end{array}$

Results $\quad 43$

Item Analysis $\quad 43$ 
Test-retest Stability

Concurrent Validity with the Multidimensional Fear of

Death Scale

Convergent and Discriminant Validity

Discussion

\section{Chapter 3}

Study 2 - Sensitivity of the Revised Collett-Lester Fear of Death and Dying Scale to an Intervention Designed to Change Attitudes Towards Death and Dying

Introduction

Method

Results

Discussion

\section{Chapter 4}

Study 3 - The Factor Structure of the Revised Collett-

Lester Fear of Death and Dying Scale

Introduction 68

$\begin{array}{ll}\text { Method } & 70\end{array}$

$\begin{array}{ll}\text { Results } & 71\end{array}$

Discussion $\quad 80$

Chapter 5

General Discussion $\quad 82$

Limitations of the Study $\quad 84$

Suggestions for Future Research 84

Reference List $\quad 86$ 


\section{List of Tables}

Page

Table 1 Lester's 1990 Factor Structure Following Principal Component Analysis and Orthogonal Rotation

Table 2 Means, Standard Deviations and Intercorrelations of the Subscales and the Total Score of the Revised CollettLester Fear of Death and Dying Scale $(n=106)$

Table 3 Item Analysis By Subscale of the Revised Collett-Lester Fear of Death and Dying Scale

Table 4 Means, Standard Deviations, and Test-retest Coefficients for each of the Subscales and Total Score for the Retest Sample $(n=70)$

Table 5 Correlates of the Multidimensional Fear of Death Subscales $(n=106)$

Table 6 Correlations of the Collett-Lester Subscales and the Multidimensional Fear Of Death Subscales

Table 7 Correlations of the Collett-Lester Subscales with Extraversion, Neuroticism, Social Desirability and Gender

Table 8 Review and Outcome of Death Education Programs $56-57$

Table 9 Group Means and Standard Deviations at Pre and Post Test 
Table 10 Principal Components Extraction $(n=106)$

Table 11 Principal Component Analysis Unrotated Factor Matrix $(n=106)$

Table 12 Principal Component Analysis with Orthogonal Rotation for the Initial Sample $(n=106)$

Table 13 Principal Components Extraction $(n=493)$

Table 14 Principal Components Analysis Unrotated Factor Matrix $(n=493)$

Table 15 Principal Components Analysis with Orthogonal Rotation $(n=493)$

Table 16 Reliability Analysis - Scale alpha Item-total Statistics $(n=493)$ 
Table of Figures

Page

Figure 1 The Original Collett-Lester Fear of Death and Dying Scale

Figure 2 The Revised Collett-Lester Fear of Death and Dying Scale

Figure 3 Subject Outline - Death Education Program

Figure 4 Non-equivalent Control Group Design

Figure 5 Scree Plot for Analysis of the Initial Sample $(n=106)$

Figure 6 Scree Plot for the Increased Sample Size $(n=493)$ 


\section{Appendixes}

Page

A. Researchers who have used the Collett-Lester Fear of Death and Dying Scale

B. The Multidimensional Fear of Death Scale

C. The EPI Short-form

D. John's Model for Structured Practice

E. Permission to use The Collett-Lester Fear of Death and Dying Scale 


\section{Chapter 1}

\section{The Measurement of Death Anxiety}

Death is the unavoidable end to life, but how, when, and where death will occur is for most people unknown. Uncertain, too, for many is the meaning of death (separation, non-existence, the beginning of a new state), how one will respond when the time of death comes (acceptance, anger, or regret), and what effects it will have on loved ones. With so many uncertainties surrounding this inevitability, some level of anxiety about death might be expected as a typical human response. Indeed, surveys of common fears indicate that fear of death is frequently reported in general community samples (Fretz \& Leviton, 1979; D'Amanda, Plumb \& Taintor, 1977; Robinson \& Wood, 1983; Ungar, Florian \& Zernitsky-

Shurka, 1990).

Although fear of death has been formally written about since at least 1896 (Durkheim, 1897; Hall, 1896; Scott, 1896) and has been an everpresent theme in literary work, scientific understanding of the concept is limited. To date, for example, there is no coherent theory of death anxiety that can assist scientific inquiry in professional practice, although a good deal of information about it has been accumulated particularly in the second half of this century. 
Kastenbaum and Aisenberg (1972) proposed, on the basis of their analysis of the literature, that fear of death is normal and similar to other fears people experience in everyday life, is multifaceted, and is learned in the course of socialization. Although fear of death is experienced more acutely in particular contexts, such as immediately following a life threatening event (Bivens, Neimeyer, Kirchberg \& Moore 1995; Catania, Turner, Choi \& Coates 1992; Hintze, Templer, Cappelletty \& Frederick, 1993) or working in death related occupations (Fang \& Howell, 1976; Hunt, Lester \& Ashton, 1983; Lattanner \& Hayslip, 1985; Neimeyer \& Dingemans, 1980), and is reported more strongly by those with higher levels of clinically defined anxiety (Lester, 1990; Lusas, 1974; Neufeldt \& Holmes, 1979; Vickio \& Cavanaugh, 1985; Wahl, 1958), it is a component of living for most people. This means that it is possible to study fear of death in samples from the normal population rather than having to resort to special sampling methods.

Fear of death is multidimensional in that it consists of a number of related fears rather than one unitary experience. The nature of these dimensions is itself a matter of continuing inquiry and debate and more will be said on this later in the thesis.

Fear of death is learned in the course of socialization. Although there is good reason to argue that evolution would favor a species wide avoidance of close contact with the dead, cultural practice with respect to the dead is highly developed and must for human beings be seen as the primary influence. Cultural practice makes us aware of our mortality at an early age and 
encourages a number of anxieties about death for reasons historically that have much to do with social control. Being learned, fears about death and dying are capable of modification like other learned fears through reeducative experiences.

These three propositions of Kastenbaum and Aisenberg (1972) serve as a framework for attempts to measure fear of death, which is the first step in developing a scientific understanding of the concept.

\section{Methods of Measuring Death Anxiety}

A number of methods have been used to measure fears about death. These range from imagery tasks (Feifel, 1955; Feifel \& Branscomb, 1973), to simple Likert scales for self-rating (Bengtson, Cuellar \& Ragan, 1977; Kalish, 1986), too more straight-forward and brief approaches such as easily scored questionnaires. Among the fantasy-based methods there have been the Thematic Apperception Test (Stroop, 1938) and the analysis of dream content (Handal \& Rychlak, 1971). Galvanic skin response, presumed to be a physiological correlate of anxiety, has been used, with reaction time, to study responses to death related word association tasks (Schultz, 1977). Researchers assumed that high galvanic skin response or slow reaction times indicate perceptual defence and, hence, death anxiety (Alexander \& Adlerstein, 1958; Feifel \& Branscomb, 1973). On the other hand, Lester and Lester (1970) found that recognition of blurred death-related words was faster than recognition of blurred neutral words and proposed that 
perceptual facilitation to death related stimuli is arguing that in an evolutionary sense, survival requires hasty recognition of threatening stimuli.

Of the various methods, the self-report mode of psychological measurement has been most widely used to assess fear of death because it purports to access the fear directly rather than through the interpretation of verbal reports, physiological change, or behavior. Although direct and straightforward, the questionnaire method has a number of weaknesses. One is summed up in 'the inventory premise', that is, the assumption that people not only can, but will, accurately reveal information about their private fears or experiences (Derogatis, Lipman, Rickels, Uhlenhuth, \& Civi, 1974). If direct access to fear of death is not possible through the individual's verbal report or if the individual is not disposed to provide that access, the questionnaire method cannot provide useful data.

Spontaneous reports about fear of death, however, point to some level of access to fears of this sort, even though some would argue that fear at an unconscious level might also exist. Examination of what is conscious or what can readily be brought to consciousness by suitable questions is itself a useful first task in the study of fear of death. As for concerns about honesty of the report being made on questionnaires, this has typically been addressed by soliciting the participant's cooperation and establishing reasonable rapport. Even if it is assumed that people can report meaningfully about their anxieties and are willing to do so, the questionnaire method faces the challenge of validity. 


\section{Construct Validity}

As Durlak and Kasimatis (1989) pointed out, demonstrating that a questionnaire has validity for the assessment of concerns about death is a difficult task. Validity refers to the degree to which a scale measures what it is supposed to be measuring (Nunnally \& Bernstein, 1994; Polit \& Hungler, 1997; Reaves, 1992; Roberts \& Burke, 1989). In some areas of research, studying the relationship between the scale and an independent criterion measure can approach the question of validity. For example, in developing measures of intelligence ratings of students' ability by their teachers served as an independent criterion. Where, however, the constructs that scales are being devised to measure have no obvious external criteria, as is frequently the case with constructs to do with personality and affect, then the validity question is addressed by accumulating a range of evidence that the scale is behaving as it should if it is capturing accurately the construct in question (Gregory, 1996; Nunnally \& Bernstein, 1994; Waltz, Strickland \& Lenz, 1991).

Construct validity is necessarily studied in a number of ways. Data indicating that a self-report scale is internally consistent, in that responses to the items that constitute it are correlated, as estimated, for example, by Cronbach's coefficient alpha, is one source of evidence for construct validity but in itself is not persuasive. The known-groups approach is considered the most basic approach to determining construct validity. The scale is administered to two groups known to be high and low on the measured 
concept. If scores for the groups differ significantly, construct validity is supported, in that the measure appears to be measuring the attribute (Polit \& Hungler, 1997; Roberts \& Burke, 1989). In the experimental manipulation approach, the attempt is made to alter scores by appropriate interventions. The extent to which scores vary as predicted provides evidence of construct validity.

Factor analysis plays an important role in validation. It is used in an exploratory fashion to summarize the structure of a group of variables. However, when a theory requires testing in respect of a structure about a particular domain then confirmatory analysis is also required (Hinkin, Tracey \& Enz, 1997). Factor analysis plays an essential part in all types of predictive and content validity for it "provides some of the tools needed to define internal structures and cross structures for sets of variables in construct validity" (Nunnally \& Bernstein, 1994, p.111).

The multitrait-multimethod approach to construct validity is based on demonstrating convergence of similar measures and divergence of measures of different constructs (Waltz, Strickland \& Lenz, 1991). Simply, convergence involves demonstrating that a scale constructed to measure a concept yields results that are similar to several other known measures of that concept when tested with the same subjects. Discriminant validity means that measures of different constructs should have low intercorrelations. It is also demonstrated when a test does not correlate with other variables or tests "from which it should differ" (Gregory, 1996, p. 145). 
This brief review of the principles of construct validity indicates that in the case such as death anxiety the following are relevant approaches; analysis of reliability, both internal consistency and stability; convergent and discriminant validity with respect too measures of similar and different constructs and factor analysis.

\section{A Review of Existing Scales}

A number of scales using the self-report questionnaire method have been reported for the measurements of concern about death. The constructs which these scales have been claimed to measure have been variously termed death anxiety (Templer, 1970), fear of death (Boyar, 1964; Collett-Lester, 1969), death concern (Dickstein, 1978), ways of coping (Bugen, 1980), and life closure (Dobratz, 1990). This section presents a brief review of the construct validity of these scales.

\section{The Lester Attitude Toward Death Scale}

The Attitude Toward Death Scale was developed in 1966 but was not published for general use until 1991 when Lester presented research evidence of the reliability and validity of the scale. It was devised as an equalinterval scale and measured two traits, general attitude toward death, and inconsistency in death attitudes. Statements about death were scaled using judges' ratings to determine the degree of favorability toward death. The median value of the items a respondent agrees to is the score for that respondent. 
In developing the scale Lester devised two parallel forms. Initially 98 statements on the subject of death were collected, numbered, sorted and then typed in book form. Students enrolled in an experimental psychology subject were invited to judge each statement on an 11-point scale for the degree to which the statement reflected a favorable attitude toward death. The final scale consists of 21 items. The respondent circles the desired agree / disagree responses. The scale values are not present on the scale for the respondents to see. They range from 1.29 to 10.76 .

Lester (1991) reported a Spearman rank correlation of .65 between the two parallel forms using a sample of 18 undergraduates. On test-retest after six weeks using 14 students, the Spearman correlation was .58. For a further 80 students and a six-week test-retest interval the Spearman rank correlation was .70 for the attitude toward death and .69 for the inconsistency score. Scores were not found to be associated with social desirability.

Lester (1991, p. 69) also pointed out that, in the initial construction of the scale, scores on the scale were found "to be associated with students' ratings of their own fear of death on a graphic rating scale" (Spearman rho $=.44, n=$ 22). Scores on the Attitude Toward Death Scale were also associated with scores on the Boyar Fear of Death Scale (Durlak, 1972; Lester, 1969), with scores on other fear of death scales, and with responses to a question on the belief in life after death (Durlak, 1979). 
Iester (1967) reported an association between scores on the scale and a history of suicidal thoughts. Relationships with scores on the scale have also been reported for poor memory for dreams (Lester, 1969), animistic beliefs (Lester, 1970a), and having less purpose and meaning in life (Durlak, 1979). Males have been reported as having higher scores than females (Krieger, Epting \& Leitner, 1974l. Nursing students with experience had less fear of death (Lester, Getty \& Kneisl, 1974), and Lester (1970b) found that religiosity was associated with an increase in favorable and overall consistent attitudes toward death.

\section{The Boyar Fear of Death Scale}

The unidimensional Boyar Fear of Death Scale was developed in 1964 to measure the intensity of fear of death. Development began with individual interviews. As a result of the data gathered, 30 items were selected as relevant. These were submitted to a panel of judges who rated them on "clarity and relevance to a specific definition" (Boyar, 1964, p.2041). As a result of this process, 22 of the 30 items were deemed suitable for inclusion in the scale.

To mask the real purpose of the scale the 22 items were included in a total of 78 other items and the package was administered to 100 subjects who were told that the purpose of the study concerned the relationship between death and child rearing attitudes. After data analysis, a further four items were deleted from the scale and it was again embedded in 54 masking questions. This time the questions related to highway safety (Boyar, 1964). 
The scale was administered to participants before and after viewing a highway accident film that was intended to increase their death anxiety. Fear of death scores rose significantly more in the experimental group than in the control group that saw an innocuous film (Schultz, 1978). Split-half reliability was .83 , and stability over a ten-day test-retest period was .79 . After analysis of the data gathered from these two experiments, Bovar (1964) concluded that the scale was internally consistent but called for factor analysis and further construct validation.

In Hoelter's (1979) study the Boyar scale failed to correlate significantly with religious orthodoxy $(r=-.08)$. However, a high correlation coefficient (.74) was found to exist between Boyar's Fear of Death Scale and Templer's Death Anxiety Scale,

\section{The Templer Death Anxiety Scale}

The Templer Death Anxiety Scale was developed in 1970 and used in over $60 \%$ of the studies published between 1978 and 1988 (Neimeyer, 1988a). In the last 11 years it has enjoyed a similar popularity. The scale provides a single measure of death anxiety. It has been translated into Chinese (Chen, 1992; Ho \& Shiu, 1995), Arabic (Abdel-Khalek, 1984), Italian (Saggino \& Kline, 1996), Portuguese (Donovan, 1993); and .Japanese (Schumaker, Warren \& Groth-Marnat, 1991). The scale consists of 15 True-False questions to tap the death anxiety level of the respondents. The items are 
scored either 0 or 1 , and a high score on the scale indicates a high degree of death anxiety.

Templer validated the scale with patients in a psychiatric hospital and with college students. High-anxiety psychiatric patients, independently assessed as such by a clinician, were found to have significantly higher death anxiety scores than the control group. Templer (1970) reported the test-retest reliability of the scale as .83 over a 3 -week period and the alpha coefficient indexing internal consistency as .76. However, Warren and Chopra (1979) and later Schell and Zinger (1984) found the scale to have poor internal consistency with split-half reliability scores of .65 and .43 respectively. Neimeyer $(1988, b)$ suggested that the low estimates of internal consistency might result from an underlying multidimensionality of scale content.

Lonetto, Fleming, and Mercer (1979) used a sample of undergraduate nursing students from both Canada and Northern Ireland plus graduate students enrolled in funeral service programs and members of the Toronto Unitarian Fellowship to study the factor structure of the Death Anxiety Scale. The sample was selected because they had varying degrees of personal experience with death and dying. The scale was administered to each of the subject groups in their own institutional setting and analyzed using principal components analysis with orthogonal rotation. Although some unique factors did appear (for example, concern over having an operation by graduate nursing students and concern over having a heart attack shown by funeral service students) four factors were common across subject groups. These 
were cognitive-affective, physical alterations, awareness of time, and stressors and pain. According to Lonetto et $\underline{\text { al }}$ (1979), awareness of time is independent of other aspects of death anxiety (this factor accounted for about $8.5 \%$ of the systematic variance of death anxiety across the five groups). The death anxiety factors that emerged from the study accounted for $64 \%$ of the systematic variance of such anxiety for each group with a range of $62 \%$ for members of the Unitarian Fellowship to $73 \%$ for graduate nursing students. They also found that only $25 \%$ of the sample could be correctly classified based on their death anxiety factor scores. Chi-squares associated with Wilk's Lambda values for the functions were not significant $(p>.30$ in all cases). Durlak (1982) argued against the continued use of the scale because of its psychometric inadequacy and factorial complexity.

Martin (1983) reported a principal-axis factor analysis of the scale using a sample of nurses. Five factors were extracted. Orthogonal rotation resulted in two items loading above $+/-.60$ on the first factor (death anxiety denial), five items loading above $+/-.40$ on the second factor (general death anxiety), five items loading above $+/-.30$ on the third factor (fearful anticipation of death), two items loading between $+/-.30$ and .76 on the fourth factor (physical death fear), and one item loading above $+/-.70$ on the final factor (fear of catastrophic death). Death anxiety denial accounted for $41 \%$ of the common variance, while the five items, which comprised the second most prominent factor, accounted for $22 \%$ of the common variance. Factors three, four, and five accounted for $15 \%, 13 \%$ and $9 \%$ of the common variance respectively. 
A later study by Gilliland and Templer (1985) found the factor structure of the scale to be unstable, as did Neimeyer (1998, p.101), who concluded, that "a given score on the instrument could represent quite different anxiety factors, whose number and interpretation shift from study to study".

Questions also surfaced regarding psychometric soundness in terms of the scale being susceptible to social desirability response bias (Dattel \& Neimeyer, 1990; Templer, 1970). In light of this and other criticism, Durlak (1982) advocated that future investigators should look to using alternative scales when embarking on studies into attitudes towards death.

\section{The Revised Death Anxiety Scale}

Nehrke (1973) combined the Templer Death Anxiety Scale with the Boyar Fear of Death Scale and added an item of his own construction. This compilation was used in a number of subsequent studies (Nehrke, Bellucci, \& Gabriel, 1978; Nehrke, Morganti, Willrich, \& Hulicka, 1979). Thorson and Powell (1994) subjected the Nehrke instrument to factor analysis and further revised it over the course of five major studies. Beginning with a 34-item true-false inventory, they reduced it to a 25 -item true-false inventory, which was subsequently changed to include responses in a five-point Likert format. Seventeen of the 25 statements which respondents are asked to either agree or disagree with are phrased positively and eight are phrased negatively. Each of these revisions was subjected to factor analysis and revealed a factor structure that varied from four to seven factors (Thorson \& Powell, 1994). 
Concurrent validity was tested when the Arabic versions of the Death Anxiety Scale and the Revised Death Anxiety Scale were administered to 274 Kuwaiti undergraduates. Cronbach coefficient alphas for the scales were .79 and .77 respectively. Pearson's correlations for scores on the two scales were .54, .67, and .64 for men, women and the combined group (Abdel-Khalek, 1997).

Test-retest reliability was examined by administering it to 277 first year medical students and again when they graduated $(n=233)$ and found to be 83 (Thorson \& Powell, 1994). Students both upon entry and upon graduation were significantly lower in death anxiety than a sample drawn from the general population. The students also completed the Edwards Personal Preference Schedule (EPPS) in their first year, a test of personality. Two low-level but significant correlations were found. One was between scores on the Revised Death Anxiety Scale and the EPPS trait of Succorance $(r=.14, p<.02)$, and the second between the Revised Death Anxiety Scale score and Heterosexuality $(r=.15, p=.02)$.

\section{The Death Concern Scale}

Dickstein's (1972) 30-item Death Concern Scale was based in part upon an earlier measure developed by Dickstein and Blatt (1966). The scale purports to measure the extent to which an individual consciously contemplates death and evaluates it negatively. Scoring produces a single score as a measure of that concern. 
Dickstein (1972) reported that internal consistency was above .85 and the test-retest reliability over an 8 -week test-retest interval was .87 . Split-half reliabilities for the male and female samples calculated separately were all above .84. Dickstein (1975) reported significant associations between the Death Concern Scale and measures on the Thematic Apperception Test. Factor analytical work carried out by Klug and Boss (1976 p.108) suggested that the scale actually contains two distinct scales, a conscious contemplation of death sub-scale of nine items and a five-item negative evaluation of death subscale. They suggested that the two subscales be scored separately.

\section{Bugen's Coping with Death Scale}

The first psychometric unidimensional self-report measure to determine death competency as a construct was Bugen's Coping with Death Scale. Death competency was defined as a range of human skills providing the individual with the ability to deal with death. Bugen (1981) developed a set of items to reflect the experiences of participants in a death and dying seminar. The specific competencies that are measured are valid death education gains, monitoring the effectiveness of a death education seminar, and emphasizing coping as a desirable outcome of a death education experience. The scale is a 30-item, seven-point Likert instrument. It has been shown to relate to the effects of Hospice training. Items fall into two categories, coping with self and coping with others. Although the scale demonstrates internal consistency $($ alpha $=.89)$ and stability over a 2 -week test-retest interval $(r=.91)$ further 
psychometric investigation is required on convergent, discriminant, construct and factorial validity (Neimeyer, 1998, a).

Robbin's (1991) study found a Cronbach's alpha of .89. A retest carried out after an eight-week interval yielded a test-retest reliability of $.91(p<.001)$. The Coping with Death Scale was significantly negatively correlated with the Templer scale. Correlations ranged from -.49 to -.60 , indicating midrange relationships and supporting convergent validity with some differentiation.

\section{The Threat Index}

Krieger, Epting, and Leitner (1974) initially introduced the Threat Index as a structured interview procedure based on Kelly's (1955) repertory grid technique. The Threat Index measures death anxiety by assessing the cognitive distance subjects place between the concepts of 'death' and 'self'. The interview-based format was time consuming, a trained interviewer taking between 60 to 90 minutes to assess a single subject (Neimeyer, Epting, \& Rigdon, 1984). To circumvent this and other complexities inherent in the structured interview method, a 200-item self-administering pencil and paper version was developed. This development not only speeded up the process, it eliminated the need to use a trained interviewer, and hence the instrument could be administered to groups and used in anonymous surveys (Neimeyer 1994). In 1979, Krieger, Epting, and Leitner refined the instrument into 75 item, 45-item, and 25-item versions that take between 15 to 30 minutes to administer. When the long and short versions were scored and compared by Durlak and Kass (1982) a correlation of .84 was obtained. 
The Threat Index is unique in that it is derived from a comprehensive theory of personality, the psychology of personal constructs, and is generally considered the most rigorously validated measure of death orientation yet published (Moore \& Neimeyer, 1991; Neimeyer \& Epting, 1992; Neimeyer \& Moore, 1989). While Schultz (1978) reported the Threat Index had poor testretest reliability $(r=0.49)$, Neimeyer $(1994$, p. 68) suggested "a number of studies have demonstrated its high internal consistency and considerable stability for periods up to 9 weeks". Internal consistency coefficients for the scale exceeded .93 , and test-retest correlation was .87 over a 9 -week period. Further, the instrument is not biased by social desirability (Dattel \& Neimeyer, 1990).

In 1988 Neimeyer, Moore, and Bagley conducted a study into the factor structure of the 30 item bipolar version of the Threat Index. This version of the scale requires the respondent in the first instant to rate their present life on a sample of 30 dichotomous (open versus closed) constructs and then to rate their personal death on the same constructs, thinking about it as if it was imminent. The total death threat score was determined by tallying scores on the construct scales.

Split scores on individual items were rotated using orthogonal, quartermax, and oblique procedures. An examination of the scree plot revealed a large first eigenvalue, with a large decline to the second and third and subsequent eigenvalues suggesting support for unidimensionality of the scale. Three 
rotated solutions presented some difficulty in interpretation. The orthogonal rotation produced six factors with at least two variables on each loading above .30. The oblique and quartermax rotation produced five and four factors respectively with nearly half the variables loading on the first factor at .40 or higher.

The self-administered form of the Threat Index was originally conceptualized as a unidimensional assessment of death concern. However, doubts have been expressed about the empirical dimensionality of the scale. Neimeyer (1994, p. 69) concluded the scale is in fact multi-dimensional in nature and these dimensions have "not been reliably established".

\section{The Multidimensional Death Anxiety Scale}

All the scales considered to this point were initially conceived on the assumption that death anxiety is a single dimension. Studies of all of these scales have, however, indicated that their item pools are multidimensional in nature. However, a number of scales have been developed from the initial assumption of multidimensionality of the construct.

The Multidimensional Death Anxiety Scale (Nelson \& Nelson, 1975) measures four dimensions of death anxiety, death avoidance, death fear, death denial, and the reluctance to interact with the dying. Each dimension is represented by a different number of questions on the 20-item scale. Each question is answered on a Likert scale, and the higher the score for each dimension the greater the individual's death avoidance, death fear, death denial or 
reluctance to interact with the dying. In 1978, Nelson re-checked the reliability of the four-dimensional solution and concluded "further refinement was clearly needed" (p. 526).

\section{The Three Death Anxiety Factor Scale}

Re-evaluating the data collected during the development phase of the Multidimensional Death Anxiety Scale and analyzing the data collected in two further research projects eventually led Nelson (1978) to develop the Three Death Anxiety Factor Scale. This scale identifies three factors related to death anxiety, and like its predecessor it purports to measure the multidimensionality of death anxiety. The scale contains 15 statements to which respondents indicate their feelings on a five-point Likert scale ranging from 'strongly agree' to 'strongly disagree'. The scores are numerically coded to indicate the strength and direction of the attitude regarding the statement. The direction of scoring varies across items in order to minimize response bias.

Three factors were identified using factor analysis (Coleman, 1993; Nelson, 1978). The first factor, 'death avoidance', loaded on five questions that measure the degree of avoidance of death symbols. The second factor, 'disengagement from death', loaded on seven questions that indicate reluctance to confront death processes. The third factor, 'fear of death', loaded on only three questions that measure the fear of personal death. 
Reliability has proven to be adequate with alpha scores for the three factors being .76, .71, and .74 (Nelson, 1978). According to Rublee and Yarber (1983, p.413) the scale is useful in that "it recognizes the multidimensions of death attitudes and can be completed in minutes". Nelson (1978) reported data on construct validity using reliability and the method proposed by Campbell and Fiske (1959). Adequate internal consistency reliability was present and a simple factor structure was produced. Nelson (1978) further showed that items comprising each of the subscales correlated more highly with each other than with items comprising other subscales and that scores on the total scale predicted choice of a health related career and choice of subjects compared with its Psychology and Sociology of death.

\section{The Fear of Personal Death Scale}

The Fear of Personal Death Scale was originally developed and written in Hebrew to investigate Israeli death fears (Neimeyer, 1998). This self-report scale developed by Florian and Kravetz (1983) measures overt expressions of death and is based on a multi-dimensional model of fear of personal death. The model conceptualized the fear of personal death to be "the personal, interpersonal, and transpersonal consequences of an individual's death" (Unger, Florian, \& Zernitsky-Shurka, 1990, p. 63). The questionnaire lists 31 reasons for fear of death to which subjects respond on a 7 -point Likert scale from 1 (totally incorrect for me) to 7 (totally correct for me). Florian and Kravetz (1983) reported adequate test-retest reliability $(.50$ to .91$)$ of the 
scale. Factor analysis showed the instrument has six factors, which together explained $67.9 \%$ of the total variance. This structure was replicated in several studies across different samples in both the Continental United States and in Israel (Florian \& Har-Even, 1983; Florian \& Snowden, 1988; Mikulincer \& Florian, 1995).

Florian and Mikulincer (1997) suggested that two factors 'fear of loss of selffulfillment' (cessation of creative activities) and 'fear of self annihilation' (decomposition of the body) correspond to the intrapersonal component of fear of death The interpersonal component is represented by the fear of loss of social identity. The transpersonal component is reflected in the fear of the unknown, and the fear of punishment in the hereafter. According to Neimeyer (1998) the scale has yet to be compared with other multidimensional death anxiety scales.

\section{The Multidimensional Fear of Death Scale}

In devising the Multidimensional Fear of Death Scale, Hoelter (1979) distributed a questionnaire containing a number of pre-tested Likert-type items to a sample of 143 male and 232 female college undergraduate students. Hoelter subjected the raw data to factor analysis with orthogonal rotation and reported a multidimensional scale consisting of 42 items and 8 dimensions. These and their alpha coefficients are: Fear of the dying process (.80), Fear of the dead (.72), Fear of being destroyed (.81), Fear for significant others (.76), Fear of the unknown (.73), Fear of conscious death (.65), Fear for body after death (.82), and Fear of premature death (.72). The mean 
internal consistency coefficient was .75 . Four of the subscales correlated positively with religious orthodoxy: fear for significant others $(r=.20, p<$ $.01)$, fear of conscious death $(r=.21, p<.01)$, fear of being destroyed $(r=.14$, $\mathrm{p}<.01)$, and fear for body after death $(\mathrm{r}=.10, \mathrm{p}<.05)$. The fear of the unknown subscale had a strong negative relationship to religious orthodoxy $(\mathrm{r}=-, 64)$

The scale was constructed to assess the many aspects of apprehension about death and dying. It has been translated into Arabic and used to examine cross-cultural fears of death among Saudi Arabian students living in the United States (Long, 1986). The scale has also been incorporated into numerous studies such as attitudes towards suicide (Hoelter, 1979), reactions to aging (DePaola, Neimeyer, Lupfer, \& Fiedler, 1992), attitudes towards fertility and death concerns (Hoelter, Whitlock, \& Epley 1979), and the death concerns of grief counselors (Terry, Bivens, \& Neimeyer, 1996).

Concurrent validity has been established in a study conducted by DePaola, et al who distributed both the Multidimensional Fear of Death Scale and the Threat Index to a sample of 145 nursing home staff and 130 matched controls. The Threat Index correlated significantly with a number of Hoelter's (1979) scale dimensions, including factor $1(\mathrm{r}=.12)$, factor $2(\mathrm{r}=.14)$, factor $4(\mathrm{r}=.21)$, and factor $5(\mathrm{r}=.13)$. The convergence of the Threat Index and the Multidimensional Fear of Death Scale provides some support for the validity of the multidimensional scale dimensions. 
Neimeyer and Moore (1994) recruited 106 undergraduates (49 male and 57 female) and administered the scale to the sample on two different occasions over a 3-week period. Pearson reliability coefficients for the eight subscales are: .77 for factor $1, .77$ for factor $2, .71$ for factor $3, .61$ for factor $4, .72$ for factor $5, .77$ for factor $6, .81$ for factor 7 , and .73 for factor 8 . A general factor comprising all items of the scale produced an $r$ of .85 .

Walkey (1982) sought to replicate Hoelter's factor structure using a sample of 256 students and their families in New Zealand. Although Walkey replicated Hoelter's (1979) study, he referred to the scale as "simply a blend of items derived from Templer's Death Anxiety Scale, Boyar's Fear of Death Scale, and other items developed by Hoelter himself" (Walkey 1982 p. 467). His concern was based on the premise that death attitudes are complex and true multidimensional scales "are not about mixing and matching unidimensional and multidimensional factors to create a multidimensional scale" Walkey (1982), however, did find strong support for the eight fear of death dimensions as proposed by Hoelter.

A further study by Long (1986) also sought to replicate the factor structure produced by both Hoelter (1979) and Walkey (1982). The translated version of the scale was administered to a group of 84 Saudi males living temporarily and studying in the United States. Using factor analysis with orthogonal rotation, Long (1986) extracted three factors which he identified as fear of dying and the dead (eight items), fear for significant others (four items), and fear of premature death (two items). Because of this result, Long (1986) 
concluded that specific fears associated with death in a Western, Christian culture were possibly not applicable to members of an Islamic society.

When scoring the scale it must be noted that lower scores on each subscale of the Multidimensional Fear of Death Scale reflect higher death anxiety. Items $3,9,14,25$, and 28 are reversed scored, that is $1=5,2=4,4=2$, and $5=1$ in order to reduce response bias.

\section{The Original Collett-Lester Fear of Death and Dying Scale}

Collett and Lester (1969) proposed that death anxiety is a multidimensional concept, and that an individual could fear the process of dying from a personal point of view and not be fearful about the dying processes of other people. Development of the 36-item Fear of Death and Dying Scale (Figure 1) focused on eliminating the problem of non-uniformity of item content in the scales used to measure fear of death up until the late sixties (Lester, 1994). The scale was considered by its developers to be sensitive to change and did not correlate with social desirability (Linn, Linn, \& Stein, 1983). Social desirability is a relevant concept because the topic of death has been and still is considered to be taboo. A conscious denial reaction suggests that the socially desirable response to a death questionnaire would be to disclaim concern.

Researchers have used the instrument to explore attitudes in dental personnel, nursing, psychology, medical and various other groups of college students (Linn, Moravec \& Zeppa, 1982; Sundin, Gaines \& Knapp, 1979; 
Cohen \&6 Parker, 1974; Hart, 1979, Robinson \&6 Wood, 1983), secondary school students (Bailis \& Kennedy, 1977), 18-69 year-olds, (Feifel \& Nagy, 1981), 60+-year-olds (Kurlychek, 1976), counselors (Larrabee, 1978), heroin addicts (D'Amanda, Plumb \& Taintor, 1977), and parents with mildly dysfunctional children (Fretz \& Leviton, 1979). It was also used to determine if systematic desensitization reduced anxiety and fear of death (Bohart $\&$ Bergland, 1979), and on people attending their family doctor for a checkup, rheumatoid arthritic sufferers, diabetics, those recently treated for cancer and a mixed group of people with no known illness (Robinson $\&$ Wood, 1983).

Concurrent validity has been established in other studies (Neimeyer \& Dingemans, 1981; Collett \& Lester, 1969; Lester, 1990) which correlated the scores on other fear of death scales with scores on the four subscales of the Collett-Lester Fear of Death and Dying Scale. The median correlation out of twelve reported sets was .57 for the Death of self subscale, .05 for the Death of others subscale, .29 for the Dying of self subscale and .17 for the Dying of others subscale (Lester, 1990). When carrying out a factor analysis both Durlak and Kass (1982) and Rigdon and Epting (1985) reported that the Lester scale score is associated with the fear of one's own death. In 1972 Durlak found concurrent validity existed between Boyar's Fear of Death Scale and the four subscales of the 36-item Collett-Lester Scale. Correlations were $.69, .58, .46$ and .40 for the Death of self, Dying of self, Death of others, and Dying of others subscales respectively. 
Here is a series of general statements. You are to indicate how much you agree or disagree with them. Record your opinion in the blank space in front of each item according to the following scale.

+1 slight agreement

+2 moderate agreement

+3 strong agreement
-1 slight disagreement

-2 moderate disagreement

-3 strong disagreement

Read each item and decide quickly how you feel about it; then record the extent your agreement or disagreement. Put down your first impressions. Please answer every item.

1) I would avoid death at all costs.

2) I would experience a great loss if someone close to me died.

3) I would not feel anxious in the presence of someone I knew was dying.

4) The total isolation of death frightens me.

5) I am disturbed by the physical degeneration involved in a slow death.

6) I would not mind dying young.

7) I accept the death of others as the end of their life on earth.

8) I would not mind visiting a senile friend.

9) I would easily adjust after the death of someone close to me.

- 10) If I had a choice as to whether or not a friend should be informed he/she is dying, I would tell him/her.

- 11) I would avoid a friend who was dying.

- 12) Dying might be an interesting experience.

- 13) I would like to be able to communicate with the spirit of a friend who has died.

- 14) I view death as a release from earthly suffering.

- 15) The pain involved in dying frightens me.

- 16) I would want to know if a friend were dying.

- 17) I am disturbed by the shortness of life.

- 18) I would not mind having to identify the corpse of someone I knew.

- 19) I would never get over the death of someone close to me.

- 20) The feeling that I might be missing out on so much after I die bothers me.

- 21) I do not think of dead people as having an existence of some kind.

- 22) I would feel uneasy if someone talked to me about the approaching death of a common friend.

- 23) Not knowing what it feels like to be dead does not bother me.

- 24) If I had a fatal disease, I would like to be told.

- 25) I would visit a friend on his/her deathbed.

- 26) The idea of never thinking or experiencing again after I die does not bother me.

- 27) If someone close to me died, I would miss him/her very much.

- 28) I am not disturbed by death being the end of life, as I know it.

- 29) I would feel anxious if someone who was dying talked to me about it.

- 30) The intellectual degeneration of old age disturbs me.

- 31) If a friend were dying, I would not want to be told.

- 32) I could not accept the finality of the death of a friend.

- 33) It would upset me to have to see someone who was dead.

- 34) If I knew a friend were dying, I would not know what to say to him/her.

- 35) I would like to see the physical degeneration of a friend who was dying.

- 36) I am disturbed by the thought that my abilities will be limited while I lie dying.

Figure 1

The Original Collett-Lester Fear of Death and Dying Scale 
While the scale showed concurrent validity with the Death Anxiety Scale (Dickstein, 1978; Vargo, 1980), the factor structure has varied across a number of studies (Durlak \& Kass, 1982; Lester, 1974; Loo \& Shea, 1996; Schultz, 1977). A cluster analysis by Livneh (1985a) using the data from 200 respondents could find no support for the four-subscale format. Livneh identified five factors, which he termed: General fear of death of self; Interaction with dying friends; Death of a friend; Avoiding meeting with dying friends, and Attitudes towards one's potential death.

The most recent study which reported on the factor and cluster structures of the 36-item version of the scale was carried out by Loo and Shea in 1996 using a sample of 45 female and 43 male undergraduate students. It should be noted, however, that the 1996 study re-examined data collected in 1984 . Principal-axis factor analysis was performed on the correlation matrix of the 36 items, and was repeated with the addition of a gender variable to elicit the role of gender in the factor structure.

Solutions ranging from two to five factors were extracted and orthogonal and oblique rotations were tabulated to determine the potential for recoverability. The two-factor solution supported the view held by Lester (1994) that the scale does distinguish between the attitude concerning death and dying of self as opposed to that of others. The four-factor solution revealed weak recovery of the four subscales and accounted for only $35 \%$ of the total variance. Cross loading on two factors presented a problem and indicated refinement of the instrument was required. Data from the two-factor solution 
revealed that items from the Death of self and the Dying of self subscales had a tendency to load on the first factor. Moreover, the subscales dealing with death and dying of others were found to load on the second factor. Loo and Shea (1996), therefore, concluded that groupings by theme differentiated between 'self' as Factor 1 as opposed to 'others' as Factor II.

Lester (1974) conducted a factor analysis on data drawn from the responses of 241 college women and found 11 factors. Only 2 of these were found to resemble the subscales as labeled. Schultz (1977) used a sample of 264 people located in a semi-rural community to analyze the scale using multidimensional scaling and a cluster analysis. He reported that the clustering of items differed between men and women.

Durlak and Kass (1982) sought to clarify the measurement of death attitudes by carrying out factor analysis on a sample of 13 representative death scales: the Fear of Death Scale, the Death Anxiety Scale, the Threat Index, the Acceptance of Death Scale, two of subscales from the Death Concern Scale, three of subscales from the Multidimensional Death Anxiety Scale, and the four subscales from the Fear of Death and Dying Scale. A principal component factor analysis with orthogonal rotation was performed on the product moment correlations between the scales for a total sample of 350 students. Principal component analysis with unities as initial commonality estimates was used and three methods were considered in determining possible factor solutions: eigenvalues greater than or equal to one, Cattell's 
(1977) scree-test, and the percentage of total variance accounted for by the factor solution.

The sample was randomly divided into two subgroups and the data for each group independently factor analyzed, the reliability of each factor solution was compared between the subgroups by computing a product moment correlation between factor loadings for corresponding factor solutions. A 'best factor' solution was determined, and factor scores for each individual computed.

Relationships between each of the death-attitude factors and other variables in the study were determined and a series of step-wise multiple regression equations were computed with each factor score as the criterion and the other variables as potential predictors. The criteria for determining the number of factors indicated three to five factors. The eigenvalue criterion indicated the extraction of three factors accounting for $59 \%$ of the total variance. Cattell's scree-test suggested five factors accounting for $70 \%$ of the total variance. Three, four, and five factor solutions were finally tested and revealed that they all replicated to a similar degree, with correlations between factors for the two sub-samples ranging from .97 to .64 for the three-factor solution, from .96 to .79 for the four-factor solution, and from .95 to .74 for the five-factor solution. The five-factor solution was accepted. Factors and their interpretations were guided by item content of the individual scales with factor loadings greater than .40. The five orthogonal factors and their relationship to the Collett-Lester Fear of Death and Dying Scale were: 
Factor I - Negative Evaluation of Personal Death. This dimension was considered to relate to the extent that the prospect of personal death arouses distress (i.e. fear, worry, depression and other negative reactions). The Death of Self subscale loaded highly on this dimension.

Factor II - Reluctance to Interact with the Dying. The Dying of Others subscale loaded highly on this dimension.

Factor III - Negative Reaction to Pain. This factor did not load on any of the Collett-Lester subscales. Durlak and Kass (1982) suggested the scales, which did not load on this factor, appeared not to measure individual reactions to pain involved in dying.

Factor IV - Reactions to the Reminders of Death. Only the Death of Others subscale loaded on this factor.

Factor V - Preoccupations with Thoughts of Dying. This factor did not load on any of the Collett-Lester subscales.

While many scales loaded on various factors the results indicated that many unidimensional scales were in fact multidimensional and that the names given to several instruments inaccurately identify the constructs being assessed (Durlak \& Kass, 1982). The Collett-Lester subscales by comparison, stood up well among the several tests examined, with three of the four subscales being recovered.

There are only two recorded instances where the test-retest reliability of the Collett-Lester scale has been examined. Larrabee carried out the first study in 1978 using a six-week test retest interval and a sample of 20 graduate 
level trainee counselors. Test-retest product moment correlation coefficients yielded $.60(p<.01)$ for Death of self, .51 $(p<.05)$ for Death of others, $.47(p$ $<.05)$ for Dying of self, and $.73(p<.001)$ for Dying of others, the average being 0.58. Rigdon and Epting (1985) carried out the second study using seven-week test retest interval. Their test retest correlations averaged 0.55. Separate correlations were not reported for each of the subscales. The evidence from both these studies is that test re-test of the original CollettLester scale is at the lower bound of what would typically be thought of as acceptable for a multi-item self report inventory.

In the 21 years between the development and the revision of the scale there are 77 recorded instances of it being used (Appendix A). Although the revised scale was published in 1990, a number of studies in which the original scale was used were published beyond that date (Gomez, Young \&. Gomez, 1991: Hayslip, Galt \& Pinder, 1994: Kaye, 1991).

\section{The Revised Collett-Lester Fear of Death and Dying Scale}

According to Lester (1990, p.452) the scale was revised "primarily to simplify the scoring system ... and to provide a more balanced number of items in each subscale". The revised scale (Figure 2) is specifically designed to measure overt (conscious) death fear and anxiety. The scale is written in English and has been translated into Chinese (Chen, 1992; Chu, 1997; Lan, 1995). 
How disturbed or anxious are you by the following aspects of death and dying? Read each item and answer it quickly. Don't spend too much time thinking about your response.

We want your first impression of how you think right now. Circle the number that best represents your feeling.

Your Own Death

1. The total isolation of death

2. The shortness of life

3. Missing out on so much after you die

4. Dying young

5. How it will feel to be dead

6. Never thinking or experiencing anything again

7. The possibility of pain and punishment during life after death

8. The disintegration of your body after you die

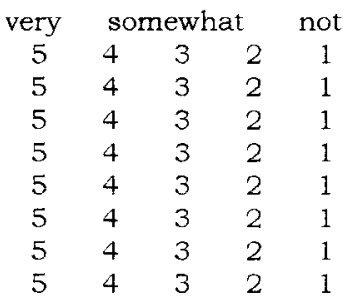

\section{Your Own Dying}

1. The physical degeneration involved in a slow death

2. The pain involved in dying

3. The intellectual degeneration of old age

4. That your abilities will be limited as you lay dying

5. The uncertainty as to how bravely you will face the process of dying

6. Your lack of control over the process of dying

8. The grief of others as you lay dying

\begin{tabular}{ccccc} 
very & \multicolumn{3}{l}{ somewhat } & not \\
5 & 4 & 3 & 2 & 1 \\
5 & 4 & 3 & 2 & 1 \\
5 & 4 & 3 & 2 & 1 \\
5 & 4 & 3 & 2 & 1 \\
& & & & \\
5 & 4 & 3 & 2 & 1 \\
5 & 4 & 3 & 2 & 1 \\
5 & 4 & 3 & 2 & 1 \\
5 & 4 & 3 & 2 & 1
\end{tabular}

The Death of Others

1. The loss of someone close to you

2. Having to see their dead body

3. Never being able to communicate with them again

4. Regret over not being nicer to them when they were alive

5. Growing old alone without them

6. Feeling guilty that you are relieved that they are dead

7. Feeling lonely without them

8. Envious that they are dead

\begin{tabular}{|c|c|c|c|}
\hline very & \multicolumn{3}{|c|}{ somewhat } \\
\hline 5 & 4 & 3 & 2 \\
\hline 5 & 4 & 3 & 2 \\
\hline 5 & 4 & 3 & 2 \\
\hline 5 & 4 & 3 & 2 \\
\hline 5 & 4 & 3 & 2 \\
\hline 5 & 4 & 3 & 2 \\
\hline 5 & 4 & 3 & 2 \\
\hline 5 & 4 & 3 & 2 \\
\hline
\end{tabular}

The Dying of Others

1. Having to be with someone who is dying

2. Having them want to talk about death with you

3. Watching them suffer from pain

4. Having to be the one to tell them they are dying

5. Seeing the physical degeneration of their body

6. Not knowing what to do about your grief at losing them when you are with then

7. Watching the deterioration of their mental abilities

8. Being reminded that you are going to go through the experience also one day

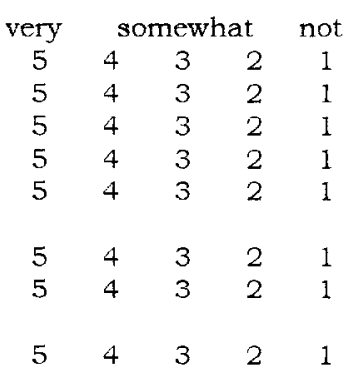

Figure 2

The Revised Collett-Lester Fear of Death and Dying Scale

A total of 32 questions are divided into four subscales, with each subscale having eight questions scored on a 5-point Likert scale. The subscales are 
designed to distinguish between the fear of death and the fear of dying and consist of questions related to one's own death and dying, and the death and dying of others.

To test for reliability Lester administered the revised format to 27 college students enrolled in psychology courses. The Pearson correlations over a two-day interval were .85 for Death of self, .79 for Dying of self, .86 for Death of others and .83 for Dying of others. However, as the test-retest period was only two days Lester called for further studies with longer test-retest time frames. Spearman-Brown correlations were $0.91,0.90,0.72$, and 0.88 , respectively.

A principal components analysis followed by orthogonal rotation on the item scores identified seven factors with eigenvalues greater than 1. Factor loadings varied and the data were not supportive of the content validity of the items contained in the scale (see Table 1). To check split-half reliability, the scale was administered to 73 adults, 22 men and 51 women. Cronbach alphas were $.91, .89, .72$, and .87 , for Death of self, Dying of self, Death of others, and the Dying of others subscales respectively. Using the same sample, correlations between the subscale scores and measures of extraversion and neuroticism from the Maudsley Personality Inventory (Eysenck, 1958) were evaluated. For both genders, neuroticism correlated significantly with fears of death and dying. For men, however, extraversion scores also correlated with fears of death and dying (Lester, 1990). 
Table 1

Lester's 1990 Factor structure following Principal Component Analysis and Orthogonal Rotation

\begin{tabular}{|c|c|c|c|c|c|c|c|}
\hline & \multicolumn{7}{|c|}{ Factor } \\
\hline & 1 & 2 & 3 & 4 & 5 & 6 & 7 \\
\hline \multicolumn{8}{|c|}{ Death of self } \\
\hline 1 & $65^{*}$ & 08 & 30 & $44^{*}$ & 11 & 10 & -03 \\
\hline 2 & $76^{*}$ & 11 & 20 & 16 & 16 & 16 & -02 \\
\hline 3 & $83^{*}$ & 06 & 04 & 03 & 09 & 16 & 18 \\
\hline 4 & $76^{*}$ & 22 & 12 & 08 & 10 & 25 & -06 \\
\hline 5 & $54^{*}$ & 21 & $49 *$ & $41^{*}$ & -02 & -05 & -13 \\
\hline 6 & $77^{*}$ & 13 & 18 & 23 & 16 & -03 & 19 \\
\hline 7 & 12 & 15 & $60^{*}$ & 11 & 32 & -09 & -51 \\
\hline 8 & $60^{*}$ & 09 & $43^{*}$ & $41^{*}$ & 01 & -01 & -11 \\
\hline \multicolumn{8}{|c|}{ Dying of self } \\
\hline 9 & 12 & 24 & 11 & 21 & $81^{*}$ & 10 & 12 \\
\hline 109 & 27 & 26 & 04 & 24 & $69 *$ & 16 & 01 \\
\hline 11 & 12 & 01 & 02 & $48^{*}$ & 35 & -01 & $49^{*}$ \\
\hline 12 & 15 & 34 & 16 & 39 & 22 & 10 & $66^{*}$ \\
\hline 13 & 16 & 25 & 03 & $77^{\star}$ & 33 & 10 & 03 \\
\hline 14 & 27 & 16 & 03 & $76^{*}$ & 17 & 15 & 16 \\
\hline 15 & 36 & 08 & $52^{*}$ & -13 & 39 & 08 & 37 \\
\hline 16 & 05 & 39 & $54^{*}$ & 12 & $40^{*}$ & -03 & 25 \\
\hline \multicolumn{8}{|c|}{ Death of others } \\
\hline 17 & 28 & $75^{*}$ & 19 & 06 & 13 & 12 & 03 \\
\hline 18 & 36 & $44^{\star}$ & 37 & -13 & -06 & $41^{\star}$ & -01 \\
\hline 19 & 29 & $58^{*}$ & 11 & 13 & 36 & -18 & -19 \\
\hline 20 & 13 & 14 & $61^{*}$ & 37 & 14 & 11 & -09 \\
\hline 21 & 07 & 16 & 35 & 26 & $61^{*}$ & 05 & 16 \\
\hline 22 & 25 & 27 & $72^{*}$ & 06 & -01 & 24 & 09 \\
\hline 23 & 35 & $69^{*}$ & 22 & 08 & 03 & -05 & 14 \\
\hline 24 & 37 & 03 & $72^{*}$ & -10 & 02 & 25 & 11 \\
\hline \multicolumn{8}{|c|}{ Dying of others } \\
\hline 25 & 15 & 17 & 13 & 14 & 25 & $79^{*}$ & 03 \\
\hline 26 & 35 & 13 & 28 & 20 & 03 & $73^{*}$ & 11 \\
\hline 27 & 12 & $56^{*}$ & -14 & -05 & $50^{*}$ & 34 & -13 \\
\hline 28 & -07 & $68^{*}$ & -04 & 16 & 34 & 33 & -02 \\
\hline 29 & -02 & $65^{\star}$ & 01 & 13 & 36 & 28 & 02 \\
\hline 30 & 05 & $74^{*}$ & 39 & 27 & -06 & 02 & -01 \\
\hline 31 & 06 & $75^{\star}$ & 18 & 21 & 20 & 08 & 30 \\
\hline 32 & 30 & 30 & 24 & $64^{*}$ & 11 & 23 & 12 \\
\hline
\end{tabular}

(Lester 1990, p. 460).

In 1993, Lester and Castromayor carried out an exploration of cross-cultural validity. They also sought to determine whether the Death Anxiety scale was more sensitive to particular fears of death and dying. Drawing their sample 
from nursing undergraduate students based in the Philippines both the Death Anxiety Scale and the 32-item Collett-Lester Fear of Death and Dying scale were administered to 18 male and 106 female students (mean age, 18.6, $\mathrm{SD}=1.4)$. Scores on the Death Anxiety Scale were strongly associated with the four Collett-Lester subscales. Scores for the Death of self, Dying of self, Others death and Others dying subscales were $(r=.36, p<.001),(r=$ $.34, p<.001),($ Pearson $r=.45, p<.001$, one-tailed), and $(r=.24, p=.004)$ respectively. Correlation by item indicated that 11 of the items of the scale correlated with the Other's death subscale, 8 items with the Own death subscale, 7 items with the Dying of self subscale, and 4 items with the Others dying subscale. Two items (2 and 15) did not correlate with any of the subscales. A principal components analysis with orthogonal rotation identified six factors indicating that the scale is "dimensionally complex" (Lester \& Castromayor, 1993, p. 114).

\section{Rationale for the Present Series of Studies}

As the preceding review makes clear, there have been several attempts to measure fear of death or death anxiety using the self-report inventory approach but construct validity for several of these attempts is lacking. One problem has been the failure of many authors to recognize the multidimensional nature of death anxiety. Of the multidimensional instruments only the Multidimensional Fear of Death Scale has a reasonably secure base in factor analytic evidence. Lester's Fear of Death and Dying Scale has a good deal of supporting evidence, at least for its initial version, 
but again its construct validity, from the point of view of its factor structure, is questionable.

The series of studies reported here was undertaken to contribute to the literature on the self-report assessment of death anxiety. Following Kastenbaum and Aisenberg's (1972) summation, death anxiety was considered a commonly experienced anxiety, multidimensional in nature, and essentially learned in the course of socialization. The Collett-Lester scale was considered a good place to begin the project because it included a number of dimensions, three of which had emerged in the Durlak and Kass (1982) factor analysis of a number of death anxiety scales. The studies were directed to clarifying basic psychometric issues with respect to the scale using more adequate sample sizes than had previously been employed, particularly with the newer revised version, and to test the construct validity of the scale in a comprehensive way.

To examine construct validity three questions were posed and each taken up in one of the three studies reported subsequently. The first concerned the relationship between the Collett-Lester scales and the scales of the Multidimensional Fear of Death Scale. The latter has the best evidence of validity based on factor analytic studies. It has, however, eight subscales and it is, therefore, of interest to determine how and to what extent the four subscales of the Collett-Lester scale match the eight of the Multidimensional Fear of Death Scales. This question was explored in Study 1, which also provided an opportunity to check internal consistency, test-retest reliability, 
and convergent and discriminant validity against measures of extraversion, neuroticism, and social desirability.

The second question concerned the sensitivity of the Collett-Lester scale to change as a result of education with respect to death and dying. Sensitivity to change is important for the validity of a measure of a construct considered to be acquired in the course of socialization and for the practical application of the scale in, for example, counseling settings. Study 2 reported here examined change in the four subscales of the Collett-Lester scale as a consequence of a 14-week course on death and dying.

The third study took up the question of factor-structure of the scale. By combining data from the first two studies and adding to these data from a third sample a sufficiently large subject sample was put together to examine in a rigorous way the match between the item parceling Lester applied in identifying subscales and the underlying factor structure of the scale. It was expected that answers to these three questions would provide a substantial increment in understanding of the self-report approach to death anxiety. 


\section{Chapter 2}

\section{Study 1}

\section{Reliability and Validity of the Revised Collett-Lester Fear of Death and Dying Scale}

\section{Introduction}

The first study in the series was directed to the question of the relationship between the Collett-Lester subscales and the Multidimensional Fear of Death Scale. For the Collett-Lester scale to show construct validity as a measure of death anxiety, it must show substantial correlations with other well-validated measures of the same construct. This is not sufficient to 'prove' its validity but it is an essential test. The Multidimensional Fear of Death Scale was selected for this purpose because it is a multidimensional test and therefore consistent with the conceptual framework of death anxiety adopted in this thesis and because of the several such instruments available the Multidimensional Fear of Death Scale had the best validated factor structure (Neimeyer, 1998a).

Examination of the content of both the Multidimensional Fear of Death Scale and the Collett-Lester scale indicated that as well as a general hypothesis that the two scales correlate substantially, it was possible to formulate specific hypotheses with respect to two of the Multidimensional Fear of Death subscales: Fear of the dying process and Fear for significant others. These subscales reflected the distinctions Lester drew between death and dying and between self and others. It was expected therefore that the first of these subscales would show stronger correlations with the Dying of self and Dying 
of others subscales than with the other two Collett-Lester subscales, whereas the second of the subscales (Fear for significant others) would show stronger correlations with the Death of others and the Dying of others subscales than with the other two subscales. Support for focused predictions of this sort would provide greater confidence that the construct as articulated by Collett and Lester was in fact being realized in their subscales.

As well as answering this first research question, the study provided an opportunity to gather more data on the internal consistency of the CollettLester subscales, their test-retest stability, and their correlations with measures of other constructs. Although Lester reported alpha coefficients for the subscales, no complete item analysis has been reported. Such an analysis provides evidence of the appropriateness of items for inclusion in the subscales and as such is a very basic test of construct validity. Testretest stability is a basic requirement of a scale purporting to measure other than a temporary mood or state. Discussion of the construct in the literature implies some durability, but Lester reported little evidence for stability over time. His only study of this using the revised version of the scale examined a two-day interval with a sample of only 27 (Lester, 1990). The test-retest correlation was .85 for Death of self, .79 for Dying of self, .86 for Death of others and .83 for Dying of others. Using the earlier version of the scale, Rigdon and Epting (1985) reported test-retest correlations, with a seven-week interval, averaging .55. Separate correlations were not reported for each subscale. 
Construct validity, as discussed in the previous chapter, is indicated by high correlations between measures of the same construct and by low correlations between measures of different constructs (Campbell \& Fiske, 1959). In the present study, a measure of neuroticism, from Eysenck's (1958) short form of the Maudsley Personality Inventory, and a measure of social desirability, a short form of the Crowne-Marlowe Scale (1960), were administered with the Collett-Lester scale. One of the most replicated of the findings with scales of death anxiety is that they relate to measures of psychopathology (Feifel, 1955; Howells \& Field, 1982; Loo, 1984a; Neimeyer \& Fortner, 1997; Westman \& Brackney, 1990). Given that neuroticism has repeatedly emerged as a major dimension of self report tests of psychopathology such as the MMPI, a relationship between neuroticism and the Collett-Lester scale was expected. Lester (1990) himself reported a positive correlation between all four subscales of the scale and Eysenck's neuroticism scale, and hence the present study must be considered an attempted replication of this.

Whereas neuroticism was expected to correlate substantially with the CollettLester subscales, a measure of social desirability was not, and too high a correlation here would in fact compromise the construct validity of the Collett-Lester scale. Although there are competing views of social desirability as an unwanted source of method variance in personality questionnaires and as a personality measure in its own right (Crowne \& Marlowe, 1964; Dickstein, 1978; Lester, 1990; Marlowe \& Crowne, 1961; Martin, 1983), it is clear that a construct such as death anxiety is separate from social desirability and hence measures of the two should not correlate. 
A measure of extraversion was obtained as part of the Eysenck Short Form. On the face of it, extraversion-introversion should not correlate with death anxiety because Eysenck constructed his measure to be independent of the neuroticism dimension with which death anxiety was expected to relate. It is of course possible for a third measure to relate to both neuroticism and extraversion, and Lester (1990) reported data of this sort. In his study ( $n=73)$, Eysenck's extraversion scale correlated with the Collett-Lester subscales of Death of self .41 , Dying of self .31 , Death of others .43 , and Dying of others .44 respectively. Using the earlier version of the Collett-Lester scale, Loo (1984) reported only moderate correlations $(.29, .35, .31$, and .33 respectively) between neuroticism and the subscales. Although conceptually there appears to be little overlap between extraversion and death anxiety, previous findings of a relationship cannot be overlooked. However, unlike neuroticism or social desirability no hypothesis was formulated in this case.

\section{Method}

\section{Participants}

A total of 106 students from two of the schools in the Health-Group at Griffith University volunteered to participate in the study. All were enrolled in a single semester human development subject conducted for 3 hours each week for 14 weeks. There were 21 males and 85 females whose ages ranged from 18 to 63 years $(\mathrm{M}=25.01, \mathrm{SD}=8.57)$. In a second data collection, 95 of the participants in the original sample provided data, but only in 70 cases 
(13 males and 57 females) could the identities of those in the initial session be determined.

\section{Materials}

The Revised Collett-Lester Fear of Death and Dying Scale (see Figure 2), the Multidimensional Fear of Death Scale (see Appendix B), and the Eysenck Personality Inventory-Short Form (see Appendix C) were administered and scored according to standard instructions.

\section{Procedure}

A letter explaining the nature and purpose of the research was circulated to a target group. They were informed that if they volunteered to take part in the study they would receive no incentives or rewards for their participation. They were also informed of the way in which the data would be used and assured that all information they provided would remain confidential. Names were not sought and gender, initials, and date of birth were used to match up the pre- and post-test data. They were also informed that as participation was voluntary they could withdraw at any time. Consent was obtained by having them sign a formal agreement before data were collected. The three questionnaires were administered in the third week of the course. Six weeks later participants again completed the Revised Fear of Death and Dying Scale as a class exercise. 


\section{Results}

All data analysis was conducted using the Statistical Package for the Social Sciences - Version 7. All variables were checked for skewness and kurtosis and a search made for outliers. Although there were some departures from normality these were judged not to be sufficient to warrant transformation of variables. The means, standard deviations, and intercorrelations of the four subscales and total score on the Collett-Lester scale for the initial sample of 106 participants are presented in Table 2. Inspection of the table indicates reasonable levels of correlations among the subscales and substantial correlations of each of the subscales with the total score.

Table 2 .

Means, Standard Deviations, and Intercorrelations of the Subscales and Total Score of the Revised Collett-Lester Scale $(n=106)$

\begin{tabular}{|lccccc|}
\hline & \multicolumn{4}{c}{ Variable } & \\
\cline { 2 - 5 } Mean & 1 & 2 & 3 & 4 & 5 \\
SD & 21.3774 & 28.8962 & 28.2453 & 27.1698 & 105.6887 \\
Intercorrelations & 7.3335 & 6.7738 & 5.8421 & 6.6196 & 21.6159 \\
\hline 1. Death of self & & & & & \\
2. Dying of self & 1.0000 & & & & \\
3. Death of others & .5374 & 1.0000 & & \\
4. Dying of others & .4858 & .4918 & 1.0000 & \\
5. Total score & .5080 & .6076 & .6707 & .0000 \\
\hline
\end{tabular}

\section{Item Analysis}

Table 3 summarizes an item-analysis of the Collett-Lester Scale conducted at the subscale level. Inspection of the table indicates that all subscales have acceptable Cronbach alpha coefficients according to the criteria proposed by Nunnally and Bernstein (1994). 
Table 3

Item Analysis by Subscale of the Revised Collett-Lester Scale.

\begin{tabular}{|c|c|c|c|c|c|}
\hline & $\begin{array}{l}\text { Scale Mean if } \\
\text { item deleted }\end{array}$ & $\begin{array}{c}\text { Scale Variance if } \\
\text { item deleted }\end{array}$ & $\begin{array}{l}\text { Corrected item } \\
\text { total correlation }\end{array}$ & $\begin{array}{l}\text { Square multiple } \\
\text { correlation }\end{array}$ & $\begin{array}{l}\text { Alpha if } \\
\text { item } \\
\text { deleted }\end{array}$ \\
\hline \multicolumn{6}{|c|}{ Death of self } \\
\hline 1 & 18.7642 & 41.6105 & .6350 & .4727 & .8148 \\
\hline 2 & 18.1604 & 40.4597 & .6896 & .6464 & .8077 \\
\hline 3 & 18.5283 & 38.6325 & .7307 & .6598 & .8004 \\
\hline 4 & 17.7453 & 42.2107 & .5415 & .4169 & .8265 \\
\hline 5 & 19.1604 & 42.0407 & .6133 & .5330 & .8175 \\
\hline 6 & 18.7170 & 40.7763 & .5868 & .3871 & .8208 \\
\hline 7 & 19.1415 & 48.7703 & .1771 & .1219 & .8691 \\
\hline 8 & 19.4245 & 42.3800 & .6673 & .5945 & .8127 \\
\hline \multicolumn{2}{|c|}{ Alpha $=.8411$} & \multicolumn{2}{|c|}{ Standardized item alpha $=.8425$} & & \\
\hline \multicolumn{6}{|c|}{ Dying of self } \\
\hline 9 & 25.2453 & 34.8916 & .5907 & .4896 & .8463 \\
\hline 10 & 25.1698 & 34.9614 & .6464 & .5367 & .8390 \\
\hline 11 & 25.2170 & 34.6668 & .5504 & .3931 & .8500 \\
\hline 12 & 25.2830 & 35.2715 & .7193 & .5741 & .8318 \\
\hline 13 & 25.7075 & 36.2660 & .5633 & .4778 & .8487 \\
\hline 14 & 25.4623 & 33.8509 & .7315 & .5870 & .8285 \\
\hline 15 & 25.2170 & 35.4287 & .6259 & .4325 & .8414 \\
\hline 16 & 24.9717 & 39.3040 & .4328 & .2366 & .8611 \\
\hline \multicolumn{2}{|c|}{ Alpha $=.8605$} & \multicolumn{2}{|c|}{ Standardized item alpha $=.8601$} & & \\
\hline \multicolumn{6}{|c|}{ Death of others } \\
\hline 17 & 23.6887 & 28.6355 & .5418 & .4691 & .7362 \\
\hline 18 & 24.6887 & 25.8164 & .5129 & .4056 & .7322 \\
\hline 19 & 24.0094 & 25.5904 & .6018 & .5235 & .7166 \\
\hline 20 & 24.9151 & 25.2403 & .5512 & .3474 & .7246 \\
\hline 21 & 24.3208 & 25.3628 & .5689 & .4848 & .7214 \\
\hline 22 & 25.5094 & 26.2142 & .4141 & .2717 & .7534 \\
\hline 23 & 24.1792 & 28.2247 & .4631 & .3797 & .7426 \\
\hline 24 & 26.4057 & 30.9482 & .1460 & .1408 & .7921 \\
\hline \multicolumn{2}{|c|}{ Alpha $=.7660$} & \multicolumn{2}{|c|}{ Standardized item alpha $=.7730$} & & \\
\hline \multicolumn{6}{|c|}{ Dying of Others } \\
\hline 25 & 24.3585 & 33.3750 & .5856 & .6369 & .8369 \\
\hline 26 & 24.8113 & 34.1355 & .5954 & .6323 & .8352 \\
\hline 27 & 22.9906 & 36.5047 & .5480 & .4371 & .8412 \\
\hline 28 & 23.3302 & 34.0137 & .6001 & .4460 & .8346 \\
\hline 29 & 23.5377 & 33.1843 & .7526 & .6395 & .8177 \\
\hline 30 & 23.6604 & 33.6740 & .5905 & .3683 & .8360 \\
\hline 31 & 23.3585 & 35.1655 & .5555 & .5023 & .8398 \\
\hline 32 & 24.1415 & 33.9703 & .5483 & .3931 & .8416 \\
\hline \multicolumn{2}{|c|}{ Alpha $=.8530$} & \multicolumn{2}{|c|}{ Standardized item alpha $=.8556$} & & \\
\hline
\end{tabular}


One item in the Death of self subscale (Item 7) and one item in the Death of others subscale (Item 24) show low item-total correlations and increases in the subscale alphas if those items were removed. Cronbach alpha for the 32 items, considered as the one scale, was .9264 .

\section{Test-retest Stability}

Table 4 summarizes the results for the test-retest stability study. For all subscales, reasonable coefficients were observed as inspection of the table indicates.

Table 4

Means, Standard Deviations, and Test-retest Coefficients for each of the Subscales and Total Score for the Retest Sample $(n=70)$.

\begin{tabular}{|c|c|c|c|c|c|}
\hline & \multicolumn{2}{|c|}{ Pretest } & \multicolumn{3}{|c|}{ Post-test } \\
\hline & $\bar{X}$ & $\mathrm{SD}$ & $\mathrm{X}$ & $\mathrm{SD}$ & $r$ \\
\hline Death of self & 20.99 & 7.42 & 20.78 & 6.66 & .85 \\
\hline Dying of self & 28.60 & 6.62 & 27.34 & 6.98 & .86 \\
\hline Death of others & 28.39 & 6.00 & 26.72 & 6.55 & .77 \\
\hline Dying of others & 27.00 & 6.15 & 25.57 & 6.85 & .83 \\
\hline Total & 26.24 & 6.55 & 25.10 & 6.76 & .82 \\
\hline
\end{tabular}

\section{Concurrent Validity with the Multidimensional Fear of Death Scale}

The intercorrelations of the eight subscales of the Multidimensional Fear of Death Scale for the initial sample of 106 participants are presented in Table 5. Inspection of the table indicates reasonable levels of correlations among the subscales, although in four instances the correlations are not statistically significant. 
Table 5

Correlations of the Multidimensional Fear of Death Subscales $(n=106)$

\begin{tabular}{|c|c|c|c|c|c|c|c|c|}
\hline & \multicolumn{8}{|c|}{ Subscale } \\
\hline & 1 & 2 & 3 & 4 & 5 & 6 & 7 & 8 \\
\hline $\begin{array}{l}\text { 1.Fear of the dying } \\
\text { process }\end{array}$ & 1.000 & & & & & & & \\
\hline $\begin{array}{l}\text { 2.Fear of premature } \\
\text { death }\end{array}$ & $.363^{\star *}$ & 1.000 & & & & & & \\
\hline $\begin{array}{l}\text { 3.Fear for significant } \\
\text { others }\end{array}$ & .153 & $.334^{* *}$ & 1.000 & & & & & \\
\hline $\begin{array}{l}\text { 4.Fear of consciousness } \\
\text { when dead }\end{array}$ & $.500^{* *}$ & $.493^{* *}$ & $.245^{*}$ & 1.000 & & & & \\
\hline $\begin{array}{l}\text { 5. Fear of being } \\
\text { destroyed }\end{array}$ & $.246^{*}$ & .112 & .005 & $.427^{* *}$ & 1.000 & & & \\
\hline $\begin{array}{l}\text { 6. Fear of body after } \\
\text { death }\end{array}$ & $.388^{* *}$ & $.393^{* *}$ & $.365^{* *}$ & $.297^{\star *}$ & .096 & 1.000 & & \\
\hline 7.Fear of the dead & $.354^{* *}$ & $.424^{* *}$ & $.357^{\star \star}$ & $.300^{* *}$ & $.348^{* *}$ & $.575^{\star *}$ & 1.000 & \\
\hline 8. Fear of the unknown & $.541^{* *}$ & $.419^{* *}$ & $.200^{\star}$ & $.250^{* *}$ & $.250^{* \star}$ & $.453^{\star *}$ & $.502^{* *}$ & 1.000 \\
\hline
\end{tabular}

Table 6 presents the correlations of each of the Collett-Lester subscales with the subscales of the Multidimensional Fear of Death Scale. An inverse relationship exists between both scales and in all cases, the subscales correlated at conventional levels of statistical significance, except for the Collett-Lester Dying of self subscale and the Multidimensional Fear of Death Fear for significant others subscale. Also shown in Table 6 are the multiple correlations of the eight Multidimensional Fear of Death subscales and each of the Collett-Lester subscales. 
Table 6

Correlations of the Collett-Lester Subscales and the Multidimensional Fear of Death Subscales.

\begin{tabular}{|c|c|c|c|c|}
\hline \multirow{2}{*}{$\begin{array}{l}\text { Multidimensional Fear of } \\
\text { Death Scale }\end{array}$} & \multicolumn{4}{|c|}{ Fear of Death and Dying Scale } \\
\hline & Death of self & Dying of self & Death of others & Dying of others \\
\hline Fear of the dying process & $-.317^{* *}$ & $-.609 * *$ & $-.321^{*}$ & 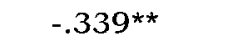 \\
\hline Fear of premature death & $-.299 * *$ & $-.333^{* *}$ & $-.475^{\star}$ & $-.410^{\star \star}$ \\
\hline Fear for significant others & $-.193^{\star}$ & -.103 & $-.213^{\star}$ & -.162 \\
\hline $\begin{array}{l}\text { Fear of consciousness } \\
\text { when dead }\end{array}$ & $-.356^{\star \star}$ & $-.487^{* *}$ & $-.524^{*}$ & $-.448^{* *}$ \\
\hline Fear of being destroyed & $-.429 * *$ & $-.327^{\star \star}$ & $-.256^{\star}$ & $-.277^{* *}$ \\
\hline Fear of body after death & $-.384^{\star \star}$ & $-.375^{\star \star}$ & $-.335^{\star}$ & $-.338^{\star \star}$ \\
\hline Fear of the dead & $-.513^{\star *}$ & $-.308^{* *}$ & $-.340^{*}$ & $-.349 * *$ \\
\hline Fear of the unknown & $-.446^{* *}$ & $-.323^{\star *}$ & $-.389^{\star}$ & $-.356^{\star \star}$ \\
\hline Multiple $R$ & .62 & .68 & .60 & .55 \\
\hline
\end{tabular}

Note: Scoring of the Multidimensional Fear of Death sub-scales is reflected with low scores indicating high anxiety, unlike the scoring for the Collett-Lester subscales, hence all coefficients have a negative sign.

$* * \mathrm{p}<.01$

$* \mathrm{p}<.05$

\section{Convergent and Discriminant Validity}

Correlations between the four Collett-Lester subscales and the Eysenck Personality Inventory-Short Form measures of neuroticism and extraversion, and the short form of the Crowne and Marlowe (1960) Social Desirability Scale are shown in Table 7 . As inspection of Table 7 indicates, there was no relationship between extraversion or social desirability and any of the four subscales. Neuroticism, on the other hand, was found to relate to the Death of others, and Dying of others subscales. Gender was found to be unrelated to any of the Collett-Lester subscales. 
Table 7

Correlations of the Collett-Lester Subscales with Extraversion, Neuroticism, Social Desirability, and Gender

\begin{tabular}{|lcccc|}
\hline & \multicolumn{5}{c|}{$\begin{array}{c}\text { Fear of Death and Dying Scale } \\
\text { Extraversion }\end{array}$} & Death of self & Dying of self & Death of others & Dying of others \\
\hline Neuroticism & .080 & .102 & .144 & .013 \\
Social desirability & .080 & .035 & $.193^{*}$ & $.238^{*}$ \\
Gender & .133 & .102 & -.129 & -.026 \\
& .107 & .182 & .098 & .009 \\
\hline
\end{tabular}

\section{Discussion}

Some of the data presented in the chapter replicate previous findings with the Collett-Lester scale, either the original or the revised format, whereas the data on the relationships with the Multidimensional Fear of Death Scale are presented for the first time. The former is discussed first.

Means and standard deviations for total score and subscale scores are comparable to those reported by Lester (1990) using an American sample of staff in a rehabilitation unit. Although differences between American and Australian samples are not to be expected given a broadly comparable culture, it is reassuring to find that the basic statistics for the scale hold up across the two countries. Likewise intercorrelations of the subscales and correlations with the total score are similar to the scores reported by Lester (1990). This level of correlation is consistent with Collett and Lester's claim that the four subscales reflect somewhat different dimensions of death anxiety. Too high or too low a level of intercorrelation would run counter to 
the hypothesis that there are discriminable facets of the single phenomenon of death anxiety.

Each of the subscales showed reasonable internal consistency, in line with Lester's (1990) report. All alpha values were larger than the .7 minimum normally proposed as acceptable for the research use of the scale (Nunnally \& Bernstein, 1994). However, two items showed low item-total correlations. Complete item analysis data for the revised version have not been reported previously and hence there are no grounds for comparison of the findings here with respect to these two items. Examination of their content does suggest some mismatch in meaning with the item clusters from which they are drawn. Item 7 (The possibility of pain and punishment during life after death) implies acceptance of survival after death and taps into a religious belief system unlike other items in the Death of self subscale. Item 24 (Envious they are dead) implies a depressive state and as such may be more related to a dimension of psychopathology than other items in the Death of others subscale. The question of the fit of these items to their respective subscales will be returned to in Chapter 4 where the results of factor analysis at the item level are reported.

The test-retest correlations for the subscales confirm Lester's (1990) findings but over a much longer time frame. Whereas, Lester used a delay of twodays, the test-retest interval here was six weeks. Use of a longer interval provides greater confidence that the stability of the scores on the subscales are not simply the result of participants recalling the answers they gave on 
the first occasion. Recall is a plausible rival hypothesis to dispositional stability with a test-retest interval of only two days, but less plausible with an interval of six weeks. Even longer intervals would dispel this alternative and provide data on just how stable anxiety of this sort is. However, with much longer intervals changes in life circumstances (e.g., accident or death in the family or social group) may intervene to change anxiety about death and dying. For present purposes, the data on the test-retest stability of the subscales, when taken with the Cronbach alphas, support the reliability of the revised version of the Collett-Lester Fear of Death and Dying Scale.

Consistent with previous findings (Dickstein, 1978; Hayslip \& StewartBussey, 1987), the Collett-Lester scale showed no significant correlation with the measure of social desirability. Social desirability bias is an important consideration in scale construction where constructs that are linked to social values are being measured. Death anxiety is one such construct and it is important therefore that response to content of the Collett-Lester scale is not confounded with desirability bias. Consistent too with previous findings (Lester, 1990; Loo, 1984) are correlations between neuroticism scores and scores on two of the subscales. Fear of death as a specific type of fear might be expected to be higher in individuals with a general disposition to anxiety or fearfulness, and several studies (Dickstein, 1978; Lester, 1990; Loo, 1984) have reported significant correlations between various measures of death anxiety and psychopathology. The potentially interesting finding here is that only two of the four subscales showed a significant correlation with neuroticism, those to do with the death and dying of others. Whether this 
indicates that some level of anxiety about one's own death is not a predictor of neuroticism whereas concerns about others death and dying are cannot be determined with the data at hand.

The results with the extraversion measure are not consistent with previous findings. Using the original version of the scale Loo (1984) reported only moderate correlations between extraversion and the four Collett-Lester subscales, while Lester (1990) using the revised version of the scale reported significant correlations between extraversion and all four subscales. By contrast the present results point to no correlation between extraversion and any of the subscales. Before attempts are made to explain the discrepancy between present and previous findings additional data are required to clarify the actual extent of any relationship.

The data considered here essentially reinforce the initial assumption of this research that the revised version of the Collett-Lester Fear of Death and Dying Scale is a good candidate for examination of the death anxiety construct in terms of its psychometric sophistication. It provides a set of internally consistent measures of a multidimensional construct, which relate and, importantly, do not relate to measures of other constructs in predictable ways. The new data generated in the present study bear on the relationship between the Collett-Lester scale and the Multidimensional Fear of Death Scale, the scale Neimeyer (1994) described as having the best factor analytic evidence of construct validity. 
It was hypothesized that the data obtained from the two sets of scales would correlate substantially as they both measured aspects of a common construct, death anxiety. For two of the subscales of the Multidimensional Fear of Death Scale, however, more specific hypotheses could be formulated. The Fear of the dying process subscale was expected to correlate more strongly with the Collett-Lester subscales of Dying of self and Dying of others than the Death of self and the Death of others, because this Multidimensional Fear of Death subscale is directed to the separation Lester made between the dying process and death itself. The Fear for significant others subscale was expected to correlate more strongly with the CollettLester death and dying of others subscales rather than the death and dying of self subscales because the Fear for significant others subscale is directed to the distinction between death and dying of self and of others.

Results supported the overall relationship of the two sets of scales. In all cases the multiple correlations between the eight subscales of the Multidimensional Fear of Death Scale and the four Collett-Lester subscales were substantial and statistically significant. The overlap between the two scales was not, however, complete. In all cases the amount of variance in the Collett-Lester subscales predictable from the Multidimensional Fear of Death Scale was less than the reliable variance in the scale, as estimated from the Cronbach alphas. That is, while both scales reflect a common construct, one scale is not wholly redundant with the other. 
Findings with respect to the specific hypotheses were less clear cut. Fear of the dying process was correlated more strongly with the Dying of Self subscale than with either Death of Self or Death of Others, but this pattern did not apply with the Dying of Others subscale. Fear for significant others subscale correlated most strongly with the Death of others subscale, but it did not correlate significantly with dying of others subscale. This may mean that the distinctions on which these specific hypotheses were based have not been captured adequately in one or both of the two scales.

In summary, the results of the first study strongly support the construct validity of the Revised Collett-Lester Scale. Previous results have been replicated and the new data on correlation with the Multidimensional Fear of Death Scale have been added. 


\section{Chapter 3}

Study 2

\section{Sensitivity of the Revised Collett-Lester Fear of Death and Dying Scale to an Intervention Designed to Change Attitudes to Death and Dying.}

\section{Introduction}

One approach to construct validity is to demonstrate that test scores are sensitive to change as a consequence of a planned intervention, when the construct in question is considered to be acquired in the course of socialization. That is, if variation in some characteristic is a result of learning, then an appropriately designed program should be able to produce re-learning and with it changes to scores on a test of the characteristic. As discussed in Chapter 1, an important guiding assumption of the present research program is that death anxiety is acquired in the course of socialization (Kastenbaum \& Aisenberg, 1972). The study reported in this chapter was undertaken to determine whether or not scores on the revised Collett-Lester scale would be changed by a program designed to reduce concerns about death.

Attempts to reduce death anxiety have resulted in a substantial literature. Table 8 provides a brief summary of this literature. Five aspects of published studies on death education programs that might be relevant to outcome were identified: the design of the study, the sample size involved, the nature of the intervention, the duration of the intervention, and the period of time over which the intervention was applied (time-frame). The design of the studies were classified as experimental, quasi-experimental, or non-experimental 
using principles proposed by Campbell and Stanley (1966). Experimental designs employed a control group, with allocation of participants to the treatment and control groups being random or quasi-random. Quasiexperimental designs employed a control group but allocation to treatment. and control was not under the researcher's control, e.g., participants self selected into the two groups. Non-experimental designs were those in which a control group was not employed and inferences about change were based solely on variation in scores over time for the treatment group. The nature of the intervention was the most difficult characteristic to code. One major difference between studies was the extent to which the intervention program used a didactic approach in which factual material about death and reactions to death were presented in an attempt to change the participant's knowledge base. Opposed to this were studies in which feelings of the participant about death were either the focus of the intervention or at least a significant consideration. The latter approach has often been described as experiential. Some studies used a mixture of the two approaches. In some cases the content of the intervention was insufficiently described to permit description. In a few cases, the didactic/experiential dichotomy was inappropriate and these have been classified separately. For each study, outcome was identified with respect to change in anxiety about death (assessed in a variety of ways but no study had used the Collett-Lester scale), even though a number of other factors may also have been considered. 
Table 8

Review, and Outcome of Death Education Programs

\begin{tabular}{|c|c|c|c|c|c|c|c|c|c|}
\hline Researcher & Date & Design & $\mathrm{N}$ & Intervention & Duration & Time frame & \multicolumn{3}{|c|}{ Outcome } \\
\hline & & & & & & & $\mathrm{SD}$ & ID & $\mathrm{I}$ \\
\hline Aday, R., \& Shanan, D. & 1995 & Non-experimental & 41 & Didactic / Experiential & $7 \mathrm{hrs}$ & 7 Weeks & & * & \\
\hline Abernathy, C. & 1980 & Non-experimental & 87 & Didactic/Experiential & 4 hrs & 1 Day & & $*$ & \\
\hline Bailis, A., \& Kennedy, G. & 1977 & Quasi-experimental & 78 & Didactic/Experiential & $7.5 \mathrm{hrs}$ & 9 Weeks & & & * \\
\hline Benvenutti, J. C. & 1991 & Quasi-experimental & 66 & Experiential & 8 hrs & 6 Weeks & & * & \\
\hline Bohart, L. B. & 1977 & Quasi-experimental & 68 & Experiential & $8 \mathrm{hrs}$ & 4 Days & & & \\
\hline Bohart, L., \& Bergland, B. W. & 1979 & Quasi-experimental & 104 & Didactic/ Experiential & 104 hrs & 6 Months & * & & \\
\hline Bugen, L. & 1981 & Quasi-experimental & 54 & Didactic/ Experiential & 45 hrs & 3 Weeks & * & & \\
\hline Catty, S., \& Tamlyn, D. & 1984 & Quasi-experimental & 55 & Didactic / Experiential & $16 \mathrm{hrs}$ & 2 Days & & * & \\
\hline Chen, J. & 1992 & Quasi-experimental & 305 & Workshop & $14 \mathrm{hrs}$ & 2 Days & * & & \\
\hline Chodi, J. \& Dulaney, P. & 1984 & Non-experimental & 44 & Workshop & 5 hrs & 1 Day & & * & \\
\hline Coleman, $\mathrm{T}$. & 1993 & Quasi-experimental & 53 & Didactic & 9 hrs & 1 Day & & * & \\
\hline Coombs, D. & 1981 & Experimental & 94 & Didactic / Experiential & $42 \mathrm{hrs}$ & 14 Weeks & & & * \\
\hline Davis-Berman, J. & 1999 & Quasi-experimental & 56 & Didactic / Experiential & $15 \mathrm{hrs}$ & 2 Days & * & & \\
\hline Durlak, J., \& Burchard & 1977 & Non-experimental & 38 & Workshop & $6 \mathrm{hrs}$ & 1 Day & & $\star$ & \\
\hline Glass. C. & 1990 & Quasi-experimental & 432 & Didactic & 8 hrs & 1 Day & * & & \\
\hline Glass, C, \& Knott, E. S. & 1984 & Quasi-experimental & 475 & Didactic & 9 Hours & 2 Weeks & & * & \\
\hline Gordon, S., \& Hallauer, D. & 1976 & Quasi-experimental & 182 & Didactic & 36 hrs & 12 Weeks & * & & \\
\hline Hurtig, W., \& Stewin, L. & 1990 & Experimental & 76 & Didactic/Experiential & $7 \mathrm{hrs}$ & 1 Day & & * & \\
\hline Hayslip, B. Galt. \& Pinder & 1993 & Quasi-experimental & 329 & Didactic / Experiential & $42 \mathrm{hrs}$ & 14 Weeks & * & & \\
\hline Hoelter, J., \&6 Epley & 1979 & Quasi-experimental & 162 & Didactic & $40 \mathrm{hrs}$ & 5 Weeks & & * & \\
\hline Johansson, N., \& Lally. & 1990 & Experimental & 54 & Experiential & $7 \mathrm{hrs}$ & 5 Weeks & & * & \\
\hline Kaye, J. & 1991 & Non-experimental & 30 & Didactic & $10.5 \mathrm{hrs}$ & 7 Weeks & & * & \\
\hline Kaye, J, \& Loscalzo, G. & 1998 & Quasi-experimental & 191 & Didactic & $42 \mathrm{hrs}$ & 14 Weeks & & * & \\
\hline Kaye, J, Gracely \& Loscalzo & 1994 & Quasi-experimental & 168 & Didactic & 36 Hrs & 12 Weeks & & * & \\
\hline Kienow, N.L. & 1992 & Quasi-experimental & 60 & Didactic & $2 \mathrm{hrs}$ & 1 Day & & * & \\
\hline Knight, K., \& Elfenbein, M. & 1993 & Quasi-experimental & 103 & Experiential & $42 \mathrm{hrs}$ & 14 Weeks & & & * \\
\hline Linn, A., Linn, C., \& Stein, D. & 1983 & Quasi-experimental & 586 & Experiential & $6 \mathrm{hrs}$ & 3 Days & & * & \\
\hline Lev & 1985 & Quasi-experimental & 75 & Experiential & 42 hrs & 14 Weeks & * & & \\
\hline
\end{tabular}

\begin{tabular}{ll|l|l}
1985 & Quasi-experimental & 75 & Experiential
\end{tabular}

42 hrs

ID - Insignificant decrease in death anxiety

I - Increase in death anxiety 
Table 8 continued

\begin{tabular}{|c|c|c|c|c|c|c|c|c|c|}
\hline Researcher & Date & Design & $\mathrm{N}$ & Intervention & Duration & Time frame & \multicolumn{3}{|c|}{ Outcome } \\
\hline & & & & & & & SD & ID & I \\
\hline Leviton \& Fretz & 1978 & Quasi-experimental & 174 & Not stated & $42 \mathrm{hrs}$ & 15 Weeks & & * & \\
\hline Leviton \& Fretz & 1978 & Quasi-experimental & 34 & Not stated & $42 \mathrm{hrs}$ & 15 Weeks & & * & \\
\hline Lockhart, $\mathrm{B}$. & 1980 & Experimental & 74 & Didactic/Experiential & $7 \mathrm{hrs}$ & 1 Day & * & & \\
\hline Lube, J. & 1977 & Non-experimental & 44 & Workshop & $12 \mathrm{hrs}$ & 2 Days & & * & \\
\hline Mansfield Privette $8 \%$ Bilbrey & 1982 & Quasi-experimental & 24 & Didactic/Experiential & $5 \mathrm{hrs}$ & 5 Weeks & & & \\
\hline McDonald, R. T. & 1981 & Quasi-experimental & 168 & Didactic & $37 \mathrm{hrs}$ & 15 Weeks & * & & \\
\hline Miles, M., S. & 1980 & Quasi-experimental & 48 & Didactic & $12 \mathrm{hrs}$ & 6 Weeks & & * & \\
\hline Molnar-Stickels & 1985 & Quasi-experimental & 233 & Didactic & $3 \mathrm{hrs}$ & 1 Day & * & & \\
\hline Mueller, M. L. & 1975 & Quasi-experimental & 125 & Didactic & $5 \mathrm{hrs}$ & 5 Weeks & & * & \\
\hline Mullins, L., \& Merriam, $\mathrm{S}$ & 1983 & Quasi-experimental & 138 & Workshop & $3.5 \mathrm{hrs}$ & 1 Day & * & & \\
\hline Murphy, P. & 1986 & Quasi-experimental & 287 & Didactic & $16 \mathrm{hrs}$ & 2 Days & * & & \\
\hline Murray, P. & 1974 & Non-experimental & 52 & Workshop & $6 \mathrm{hr}$ & 1 day & & * & \\
\hline Murray-Frommelt, K. H. & 1991 & Non-experimental & 34 & Workshop & $2 \mathrm{hr}$ & 1 Day & * & & \\
\hline Nash, M., Connors \& Gemperle & 1977 & Non-experimental & 83 & Workshop & $11 \mathrm{hrs}$ & 5 Weeks & * & & \\
\hline Noland, M., Richardson \& Bray & 1980 & Quasi-experimental & 274 & Didactic & $8 \mathrm{hrs}$ & 16 Days & * & & \\
\hline Rosenthal, N. R. & 1980 & Quasi-experimental & 45 & Didactic & $15 \mathrm{hrs}$ & 18 Weeks & * & & \\
\hline Rublee, D., \& Yarber, W. L. & 1983 & Experimental & 106 & Didactic & $3-9 \mathrm{hrs}$ & 3 - Weeks & & * & \\
\hline Shoemaker, R., et al & 1981 & Non-experimental & 93 & Didactic & $9 \mathrm{hrs}$ & 11 Weeks & * & & \\
\hline Schachter & 1977 & Non-experimental & 15 & Didactic & $14 \mathrm{hrs}$ & 7 Weeks & & * & \\
\hline Testa, J. A. & 1981 & Quasi-experimental & 48 & Didactic & $4 \mathrm{hrs}$ & 5 Weeks & & * & \\
\hline Trent, C., \& Glass, J. C. & 1980 & Non-experimental & 59 & Didactic & $2 \mathrm{hrs}$ & 2 Weeks & * & & \\
\hline Trent, C., Glass \& McGee & 1980 & Quasi-experimental & 200 & Didactic/Experiential & $12 \mathrm{hrs}$ & 6 Weeks & * & & \\
\hline Wass, N., et al & 1980 & Quasi-experimental & 296 & Didactic & $24 \mathrm{hrs}$ & 4 Days & & * & \\
\hline Watts, P. & 1977 & Non-experimental & 75 & Didactic & $5 \mathrm{hrs}$ & 5 Weeks & * & & \\
\hline Whelan, W., 8 Warren, W. & 1980 & Non-experimental & 31 & Workshop & $6 \mathrm{hrs}$ & 1 Day & & * & \\
\hline Yarber, W., Gobel 8: Rublee & 1981 & Quasi-experimental & 47 & Didactic/Experiential & $45 \mathrm{hrs}$ & 15 Weeks & & * & \\
\hline Yates, P., Clinton \& Hart & 1966 & Non-experimental & 181 & Didactic/Experiential & $42 \mathrm{hrs}$ & 14Weeks & * & & \\
\hline Yeaworth, R., Knapp \& Winget & 1974 & Quasi-experimental & 267 & Didactic/Experiential & $90 \mathrm{hrs}$ & 30 Weeks & * & & \\
\hline
\end{tabular}

\begin{tabular}{l|l|l|l} 
Yeaworth, R., Knapp \& Winget & 1974 & Quasi-experimenta
\end{tabular}

Legend: SD - Significant decrease in death anxiety

ID - Insignificant decrease in death anxiety

I - Increase in death anxiety 
Outcome was assessed in terms of direction (an increase versus a decrease in anxiety) and, for those studies showing the expected decrease, its statistical significance (significant at the conventional .05 level or better or nonsignificant).

Inspection of Table 8 shows that most studies reported a decrease in anxiety although a few interventions produced a paradoxical increase in anxiety. Outcome did not always reach conventional levels of statistical significance, with the preponderance ( 28 of 51 ) in fact being non-significant. The overwhelming result, however, is that death anxiety decreases with a wide variety of interventions directed at producing such a result.

Inspection of Table 8 does not help clarify the circumstances in which a significant outcome of the intervention is to be predicted. It was expected initially that careful analysis in terms of the major aspects of the studies would identify those characteristics most responsible for a significant outcome. Neither the quality of the study (type of design and power as indexed by sample size), on the one hand, nor the type of intervention (approach and duration), on the other, provide a simple formula for success. The latter finding was important in that it provided no guidance for how to design an intervention for the present study.

The intervention used in this study was a didactic/experiential approach consisting of a total of 42 hours over a 14-week period, and delivered as a subject taught for credit in an undergraduate course. The goals of the 
subject were: Increased understanding of the theoretical underpinnings related to death and dying, recognizing the value of reflection and journalling as a vehicle facilitating personal growth and professional development, understanding personal attitudes related to death, dying and the role socialization plays in attitude formation and resolving personal feelings about one's own death and others dying. Combinations of various learning activities were used in the course. The first hour was dedicated to factual material underpinning the themes presented each week (see Figure 3) followed by various activities (e.g. value clarification exercises) designed to help the students interact and explore various dimensions of personal feelings, related thoughts and behaviors, and, legal and ethical issues.

"Experiential programs may use some of the same instructional techniques as didactic programs to convey information about death, but their ultimate goal is to help individuals examine and discuss their personal feelings and concerns about death" (Durlak \& Riesenberg, 1991, p.42-43). The program was not designed to manipulate the student's fear of death directly. Rather the goal was to instill a deeper understanding of self, one's meaning, purpose, and place in life. It also sought to develop a sense of competence in those providing services to individuals who are dying and recognition of one's own ability to cope with death and death related incidents. 


\begin{tabular}{|c|c|c|}
\hline Week & Topic & Activity \\
\hline 1 & $\begin{array}{l}\text { Introduction- primary } \\
\text { determinants of behavior, self } \\
\text { awareness and reflective } \\
\text { practice }\end{array}$ & $\begin{array}{l}\text { Readings - refer to study guide. } \\
\text { Commence journalling. }\end{array}$ \\
\hline 2 & $\begin{array}{l}\text { Death Happens - Death is - } \\
\text { Sudnow's } 1967 \text { psychological, } \\
\text { biological, social and } \\
\text { physiological constructs. }\end{array}$ & Readings - refer to study guide \\
\hline 3 & Attitudes towards Death & $\begin{array}{l}\text { Guided reading and associated } \\
\text { activities }\end{array}$ \\
\hline 4 & Cultural perspectives on Death & $\begin{array}{l}\text { Guided reading and associated } \\
\text { activities }\end{array}$ \\
\hline 5 & Socialization and Death & $\begin{array}{l}\text { Guided reading and associated } \\
\text { activities }\end{array}$ \\
\hline 6 & Health Care Systems & $\begin{array}{l}\text { Guided reading and associated } \\
\text { activities. }\end{array}$ \\
\hline 7 & Facing Death & $\begin{array}{l}\text { Guided reading and associated } \\
\text { activities }\end{array}$ \\
\hline 8 & Survivors and Death & $\begin{array}{l}\text { Guided reading and associated } \\
\text { activities }\end{array}$ \\
\hline 9 & Last Rites & $\begin{array}{l}\text { Guided reading and associated } \\
\text { activities }\end{array}$ \\
\hline 10 & The Law and Death & $\begin{array}{l}\text { Guided reading and associated } \\
\text { activities }\end{array}$ \\
\hline 11 & $\begin{array}{l}\text { Death in the Lives of Children } \\
\text { and Adolescents }\end{array}$ & $\begin{array}{l}\text { Guided reading and associated } \\
\text { activities }\end{array}$ \\
\hline 12 & Death in the Lives of Adults & $\begin{array}{l}\text { Guided reading and associated } \\
\text { activities }\end{array}$ \\
\hline 13 & $\begin{array}{l}\text { Environmental Encounters with } \\
\text { Death }\end{array}$ & $\begin{array}{l}\text { Guided reading and associated } \\
\text { activities }\end{array}$ \\
\hline 14 & Who Cares for the Carers? & $\begin{array}{l}\text { Guided reading, reflection and } \\
\text { journalling and evaluation }\end{array}$ \\
\hline
\end{tabular}

Figure 3

Death Education Program - Subject Outline 
Following a weekly one-hour didactic lecture students engaged in further 2 hour sessions of sequenced exercises and activities designed to help them understand life and death issues. Reflection and journalling were also central to the student's learning process (Hendricks, Mooney \& Berry, 1996, p. 98). A model for structured reflection designed by Johns (see Appendix D) was also utilized in experiential sessions as a way of helping the students to critically appraise and evaluate their experiences both on a personal and professional level (Mooney, 1998).

The study reported here sought to test whether scores in the Revised CollettLester Scale decreased as a result of exposure to this death education program.

A quasi-experimental, non-equivalent control group design was used (see Figure 4). This design is very similar and often confused with a true experimental design. However, in order to carry out a true experimental design three conditions are necessary: manipulation, control, and randomization (Reaves, 1992; Roberts \& Burke, 1989). In cases where subjects cannot be assigned at random to either treatment or non-treatment groups, true experiments are not possible. In order to overcome this difficulty the quasi-experimental non-equivalent comparison group design is a useful substitute. The conditions for a true experiment could not be met in conducting the present study because the students could not be randomly allocated to groups. 
Time line of study events

\[ \begin{array}{l}\text { Pretest } \\ \text { GROUPS }\end{array} \]
Experimental

Figure 4

Because total experimental control is absent the quasi-experimental design does not necessarily provide the same assurance as a true experiment in determining cause and effect between the independent and dependent variable. If participants are not randomly assigned to groups the design is weaker in terms of assuming that the experimental and comparison groups were equal at the start of the study. This study is none the less a strong substitute for a true experiment in that the collection of pre-test data allows for determining whether the groups were initially similar in terms of their level of fear (Polit \& Hungler, 1997)

\section{Method}

Data were gathered from undergraduate nursing students attending courses held on the Griffith University - Gold Coast campus. The target population was invited to participate in the study and a letter explaining the nature and purpose of the research was circulated. They were informed that if they 
volunteered to take part in the study there would be no incentives or rewards for their participation. They were informed of the way in which the data would be used and assured that any identifying data (their initials and date of birth) would remain confidential. Their gender, initials, and date of birth were used to match the pre - with post-test data. They were also informed that as their participation was voluntary and that they could withdraw at any time. Consent was obtained by having the subjects sign a formal agreement before they were issued the instrument.

The experimental group consisted of students who completed a single semester experiential/didactic death education program conducted over 3 hours each week for 14 weeks, as an elective subject.

The Revised Collett-Lester scale was administered to the experimental group at the beginning of the first week of the program and was completed by 122 subjects. Eight questionnaires $(6.5 \%)$ were rejected, as the information supplied was either incomplete or misleading (e.g. failed to respond to numerous questions or indicated multiple responses to a number of questions), and hence $n=114$. Immediately on completion of the program the scale was administered a second time and was completed by 99 subjects. Twelve questionnaires $(8 \%)$ were subsequently rejected because of difficulties in matching the pre and post data sets, and hence $n=87$. The attrition rate from the initial to second testing was $22 \%$. 
The subjects who formed the control group were selected on the basis that they, like the experimental group, were undergraduate students at the same academic level, who had enrolled in a program of similar structure, design and duration as the death education program, that is, a program that was conducted 3 hours each week for 14 weeks. They had not previously participated in a death education program.

As with the experimental group the Collett-Lester scale was administered to the control group at the beginning of the first week of the program and completed by 146 subjects. Seventeen questionnaires were rejected, as the information supplied was either incomplete or misleading ( $n=129)$. Immediately on completion of the program the instrument was administered a second time and was completed by 127 subjects. Five questionnaires were subsequently rejected because information supplied by the respondent was incomplete or missing, and hence $n=122$.

\section{Results}

The means and standard deviations for scores on each of the four subscales in the revised Collett-Lester scale at pre and posttest for the experimental and comparison groups are presented in Table 9. When the pretest and posttest data are compared a marked difference in the scores is apparent. The posttest scores for the experimental group decreased whereas the posttest scores for the control group increased. 
A multiple discriminant analysis comparing the two groups in terms of the four subscales at pretest found no overall difference between the groups (Wilks Lambda $=.982$, chi-square $=4.405, \mathrm{df}=4, \mathrm{p}>.3$ ). Comparisons of individual means indicated that only in the case of the Dying of self subscale was the $F$ greater than 1 , but this was not significant $(F 1,241=2.44, p>.1$. At posttest, multiple discriminant analysis indicated a statistically significant separation of the two groups (Wilks Lambda $=.861$, chi square $=30.574, \mathrm{df}=$ 4, $\mathrm{p}<.0001)$. Comparison of individual means indicated significant differences for three of the four subscales: Dying of self $(F 1,207=9.66, p<$ $.001)$, Death of others $(\mathrm{F} 1,207=17.216, \mathrm{p}<.001)$, and Others dying $(\mathrm{F}$ $1,207=24.172, p<.001)$. The comparison for the Death of self subscale was not significant $(\mathrm{F} 1,207=1.703, \mathrm{p}>.1)$.

Table 9

Group Means and Standard Deviations at Pre and Posttest

\begin{tabular}{|lllll|}
\hline & \multicolumn{2}{c}{ Pretest } & \multicolumn{2}{c|}{ Posttest } \\
Experimental Group & $\mathrm{M}$ & $\mathrm{SD}$ & $\mathrm{M}$ & $\mathrm{SD}$ \\
\cline { 2 - 4 } Death of self & & & & \\
Dying of self & 23.13 & 7.841 & 20.85 & 6.882 \\
Death of others & 30.52 & 6.8034 & 28.97 & 6.035 \\
Dying of others & 26.61 & 4.671 & 23.86 & 6.245 \\
Control Group & 25.73 & 5.775 & 22.60 & 5.224 \\
Death of self & & & & 8.187 \\
Dying of self & 22.54 & 7.802 & 24.20 & 6.998 \\
Death of others & 29.09 & 7.338 & 30.19 & 6.202 \\
Dying of others & 26.89 & 6.0367 & 27.48 & 6.213 \\
\hline
\end{tabular}




\section{Discussion}

The results of the present study are clear in showing statistically significant differences in the expected direction for three of the four sub-scales of the Collett-Lester scale between the experimental and comparison groups at posttest where none existed at pretest. As such the present data are consistent with the bulk of previous studies summarized in Table 8 showing the effectiveness of intervention programs in reducing death anxiety. This demonstrated sensitivity of the scale to an intervention predicted to change scores on the scale provides support for its construct validity.

Two aspects of the findings of the present study deserve further comment. The first is that the Death of self subscale, unlike the other three, failed to show a significant decrease in score. That this is simply a Type 2 error arising from the power of the test being made is unlikely in view of the significant findings with the other subscales. It may be that death of self is more central to the individual's knowledge and belief system and as such requires a more powerful or longer lasting intervention to change. This, of course, is speculative and replication of the present findings is in order before much is made of it.

The second aspect is that the significant result arose from decreases at posttest in the experimental group coupled with slight increases in the comparison group over pretest levels. Increases in scores were not expected in the comparison group. In study 1 (see page 46), for example, scores on retest 6 weeks after initial administration decreased, although only slightly. 
Had scores in the comparison group not increased, the result of the present study may not have been as clear-cut as it was. This observation prompted an inquiry about the circumstances in the comparison group that might have resulted in the unexpected increase. One salient finding was that a subsample of the comparison group had accepted an invitation to visit an anatomy laboratory as part of a class exercise in the subject Human Anatomy and Physiology. For the majority of the students this visit would be their first encounter with a cadaver or human body parts. Wear (1989) reported that students are apprehensive about handling body parts in the days leading up to their first visit to an anatomy laboratory while Ersland, Weisaeth and Sund (1989) and Gustavson (1988) reported that anticipation of encountering and handling a cadaver for the first time is anxiety provoking. Similar effects on these students may have resulted in the slight increase in means at post-test reported in Table 9. As students were not asked to identify themselves it was not possible to match participants with a list of those attending the anatomy laboratory. In hindsight the use of students in this subject as the comparison group was not the wisest choice.

The finding of increased scores in the comparison group compromises the conclusion about construct validity of the revised Collett-Lester scale. Although the increases were slight, it remains to repeat the present study using a more neutral comparison before an unequivocal conclusion can be reached. 


\section{Chapter 4}

Study 3

The Factor Structure of the Revised Collett-Lester Fear of Death and

\section{Dying Scale}

\section{Introduction}

Fear of death, as discussed in Chapter 1, is now generally considered to be multi-dimensional. Lester (1990) in developing his scale proposed, on the basis of a rational analysis of the construct of death anxiety, that there should be four basic dimensions depending on whether the target of the anxiety was self or others and on whether it was the idea of death itself or the process of dying that was a concern. This four-dimensional structure guided both the development of the original scale and in its revision. An important demonstration of construct validity would thus be recovery of four dimensions from factor analysis of scores on the 32 items of the revised Collett-Lester scale.

As reported in Chapter 1, there have been six factor analytic studies to date of the Collett-Lester scale, five with the original version (Durlak \& Kass 1982; Lester 1974; Livneh 1985; Schultz 1977; Loo 8. Shea 1996) and one with the revised version (Lester, 1990). In five of these six analyses, more than four factors were recovered. Durlak and Kass (1982) reported five factors, Lester (1974) eleven factors, Livneh (1985) five factors, Schultz (1977) reported a multidimensional scaling and cluster analysis of the items contained within the scale and thus presented the results in a series of two-dimensional maps indicating that the clustering of items differed between men and women, and 
Lester (1990) seven. Loo and Shea (1996) forced a four factor solution but found this accounted for only $35 \%$ of the total variance and the four factors showed a mix of item loadings across the four subscales.

In considering the results of factor analytic studies, a number of considerations need to be borne in mind (Gregory 1996; Hinkin, Tracey \& Enz 1997; Kachigan 1986; Roberts \& Burke 1989). One is the sample size on which the analysis is based. Although experts do not agree on the optimal sample size and a number of rules of thumb have been provided (e.g., a minimum of 5 subjects per variable according to Nunnally \& Bernstein, 1994), it is generally accepted that larger sample sizes are generally to be preferred to smaller sample sizes. The majority of factor analytic studies of the Collett-Lester to date have used relatively small sample sizes. Loo and Shea (1996), for example, used 88 and Lester himself used a sample of 73 in the only study that has examined the revised form of the scale. If the Nunnally and Bernstein (1994) criteria of 5 subjects per variable is applied then a minimum sample size for factor analysis of the 32 -item scale would be 160. A second consideration is the number of factors to extract. Again experts are divided, with the criterion of eigenvalues of 1 or greater being widely accepted and Cattell and his supporters using inspection of the trace line (the scree test) to determine the number. A third consideration is the method of rotation of extracted factors to aid in their interpretation. Orthogonal rotations such as Varimax in which all factors are independent of each other have come to be used widely by previous researchers into the Collett-Lester Fear of Death and Dying scale. 
The present study takes up the question of the factor-structure of the Revised Collett-Lester Fear of Death and Dying scale. An exploratory factor analysis of the scale at the item level was conducted using the Statistical Package for the Social Sciences (SPSS version 7). Principal components analysis with orthogonal rotation was applied and factors determined using Cattell's scree-test. Orthogonal rotation was applied to maintain consistency with the methods used by previous researchers. The analysis was conducted in two phases, first using a sample of 106 (the data from the participants in Study 1) and then using a much larger sample $(n=493)$, to check whether sample size is responsible for the differing outcomes to date with respect to the number of factors comprising the scale.

\section{Method}

The pretest data supplied by the 106 participants who took part in Study I were used as one sample, providing approximately 3 participants per item. The second sample combined the data from the first sample with the pretest data supplied by the 243 subjects who took part in Study 2 . Then, specifically for the purpose of increasing the sample size further, data were obtained from another 144 subjects. Thus the data from a total of 493 subjects were available for analysis, or approximately, 15 participants per item. The additional sample matched in all respects those studied in Studies 1 and 2 . That is, they were students enrolled in single semester subjects within the Health Group at Griffith University. Their ages ranged from 17 to 
55 years, $80 \%$ were female, and they had not previously taken part in a death education program.

\section{Results}

Analysis of the data for Sample 1 using principal components analysis identified eight factors with eigenvalues of 1 or greater (see Table 10).

Table 10

Principal Component Extraction ( $n=106)$

\begin{tabular}{|c|c|c|c|}
\hline Factor & Eigenvalue & $\begin{array}{l}\text { Percentage of } \\
\text { variance }\end{array}$ & $\begin{array}{l}\text { Cumulative } \\
\text { percentage }\end{array}$ \\
\hline 1 & 10.51961 & 32.9 & 32.9 \\
\hline 2 & 2.67675 & 8.4 & 41.2 \\
\hline 3 & 2.31626 & 7.2 & 48.5 \\
\hline 4 & 1.82016 & 5.7 & 54.2 \\
\hline 5 & 1.46188 & 4.6 & 58.7 \\
\hline 6 & 1.23121 & 3.8 & 62.6 \\
\hline 7 & 1.14180 & 3.6 & 66.1 \\
\hline 8 & 1.05732 & 3.3 & 69.5 \\
\hline 9 & .84671 & 2.6 & 72.1 \\
\hline 10 & .83092 & 2.6 & 74.7 \\
\hline 11 & .74059 & 2.3 & 77.0 \\
\hline 12 & .67222 & 2.1 & 79.1 \\
\hline 13 & .62829 & 2.0 & 81.1 \\
\hline 14 & .60342 & 1.9 & 83.0 \\
\hline 15 & .57592 & 1.8 & 84.8 \\
\hline 16 & .54155 & 1.7 & 86.5 \\
\hline 17 & .49783 & 1.6 & 88.0 \\
\hline 18 & .46496 & 1.5 & 89.5 \\
\hline 19 & .43135 & 1.3 & 90.8 \\
\hline 20 & .36242 & 1.1 & 91.9 \\
\hline 21 & .33280 & 1.0 & 93.0 \\
\hline 22 & .31792 & 1.0 & 94.0 \\
\hline 23 & .29802 & .9 & 94.9 \\
\hline 24 & .27268 & .9 & 95.8 \\
\hline 25 & .24389 & .8 & 96.5 \\
\hline 26 & .22959 & .7 & 97.2 \\
\hline 27 & .18908 & .6 & 97.8 \\
\hline 28 & .16845 & .5 & 98.4 \\
\hline 29 & .16468 & .5 & 98.9 \\
\hline 30 & .13444 & .4 & 99.3 \\
\hline 31 & .12218 & .4 & 99.7 \\
\hline 32 & .10517 & .3 & 100.0 \\
\hline
\end{tabular}


The first four factors accounted for $54.2 \%$ of the total variance, while the remaining four factors accounted for a further $10.8 \%$ of the total variance. Although eight factors emerged, Cattell's scree-test suggests a four factor or a five factor solution (see Figure 5). Four factors were extracted (see Table 11) and rotated by varimax (see Table 12).

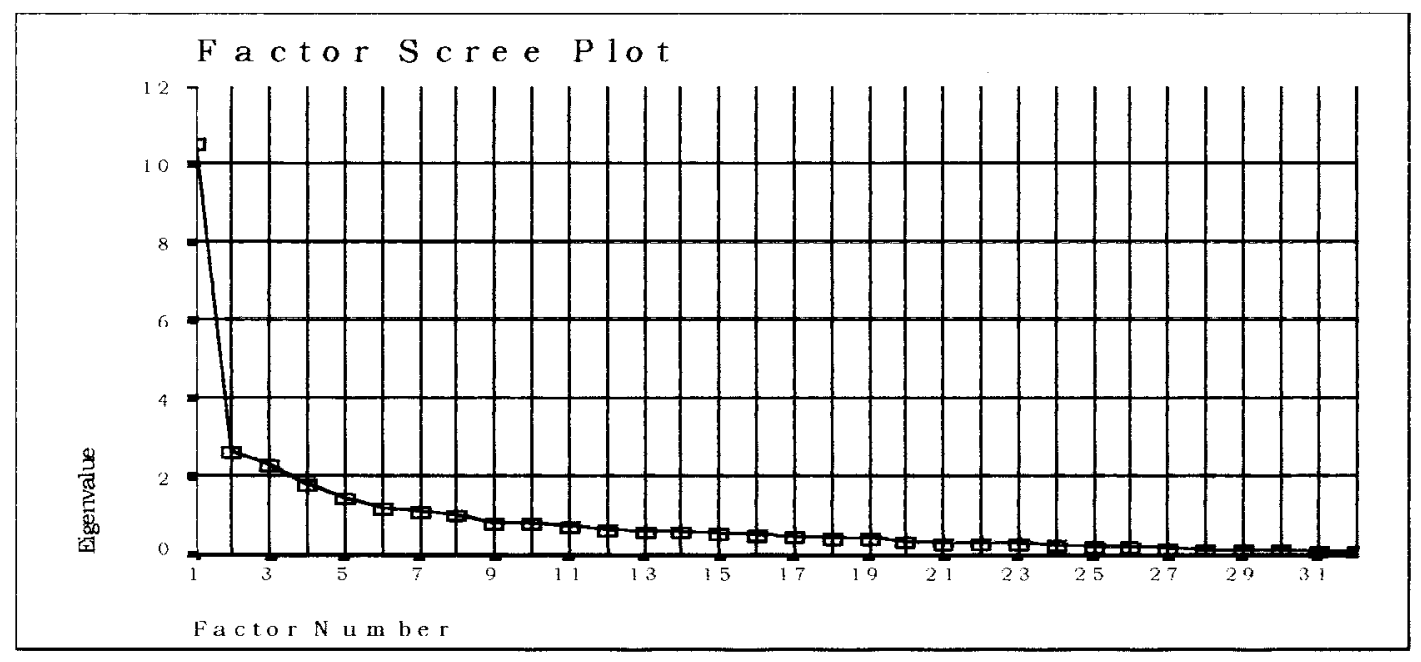

Figure 5. Scree plot for analysis of the initial sample $(n=106)$

Inspection of Table 12 shows Factor 1 has salient loadings (>. 40) on item 7 in the Death of self subscale, items $8,9,10,11,12,13,14$, and 15 in the Dying of self subscale, and items 28,29, and 31 in the Dying of others subscale. Factor 2 has loadings on items 2 and 4 in the Death of self subscale, 15 and 16 in the Dying of self subscale, 17, 19, 21, and 23 in the Death of others subscale and 27,28 , and 30 in the Dying of others subscale. Factor 3 is strongly defined by loadings on items $1,2,3,4,5,6$ and 8 in the Death of self subscale. Factor 4 has loadings on items 18, 19, 20, and 22 in the Death of others subscale and further loadings on items $25,26,29$, and 32 in the 
Dying of others subscale. Items 2 and 4 cross load on Factors 2 and 3. Item 15 crossloads (at the >. 30 level) on Factors 1 and 2, as does 19 on Factor 2 and 4, item 28 on Factor 1 and 2, and item 29 on Factor 1 and 4. Item 24 does not load meaningfully on any of the factors.

Table 11

Principal Component Analysis - Unrotated Factor Matrix $(n=106)$

\begin{tabular}{|c|c|c|c|c|}
\hline & Factor 1 & Factor 2 & Factor 3 & Factor 4 \\
\hline \multicolumn{5}{|c|}{ Death of self } \\
\hline 1 & .51887 & .26038 & -.44291 & -.14988 \\
\hline 2 & .66976 & .21699 & -.31990 & -.34889 \\
\hline 3 & .63866 & .33810 & -.35258 & -.21475 \\
\hline 4 & .60335 & .02360 & -.32932 & -.39404 \\
\hline 5 & .41942 & .58753 & -.36584 & .16697 \\
\hline 6 & .56510 & .32455 & -.21492 & .12869 \\
\hline 7 & .25502 & -.01946 & -.17726 & .51321 \\
\hline 8 & .53940 & .52433 & -.32070 & .23434 \\
\hline \multicolumn{5}{|c|}{ Dying of self } \\
\hline 9 & .54051 & -.32491 & -.43549 & .14179 \\
\hline 10 & .57038 & -.32287 & -.30048 & .18745 \\
\hline 11 & .49272 & -.43801 & -.07915 & .27252 \\
\hline 12 & .61800 & -.33455 & -.18489 & .30599 \\
\hline 13 & .65276 & -.07027 & -.03638 & .03890 \\
\hline 14 & .68447 & -.32995 & -.14332 & .21292 \\
\hline 15 & .73903 & -.19086 & .08725 & -.03497 \\
\hline 16 & .45271 & -.36848 & .00130 & -.20045 \\
\hline \multicolumn{5}{|c|}{ Death of others } \\
\hline 17 & .67417 & -.15522 & -.04437 & -.30656 \\
\hline 18 & .62072 & .16490 & .17991 & .02733 \\
\hline 19 & .66018 & .14429 & .21272 & -.24742 \\
\hline 20 & .53603 & .07270 & .38059 & .03825 \\
\hline 21 & .56954 & -.05250 & .23905 & -.40621 \\
\hline 22 & .37075 & .28381 & .40918 & .20330 \\
\hline 23 & .55332 & -.04662 & .16710 & -.42561 \\
\hline 24 & -.07841 & .36966 & .36295 & -.03089 \\
\hline \multicolumn{5}{|c|}{ Dying of others } \\
\hline 25 & .55478 & .41265 & .30397 & .22893 \\
\hline 26 & .53882 & .43584 & .30737 & .29960 \\
\hline 27 & .52487 & -.27437 & .24946 & .01837 \\
\hline 28 & .64396 & -.17215 & .22614 & .06452 \\
\hline 29 & .71583 & -.05798 & .20668 & .13816 \\
\hline 30 & .66815 & -.09662 & .24157 & -.21178 \\
\hline 31 & .57453 & -.35069 & .23576 & .20281 \\
\hline 32 & .61357 & .14646 & .23502 & .05358 \\
\hline
\end{tabular}


Table 12

Principal Component Analysis with Orthogonal Rotation for Initial Sample $(n=106)$.

\begin{tabular}{|c|c|c|c|c|}
\hline & Factor 1 & Factor 2 & Factor 3 & Factor 4 \\
\hline \multicolumn{5}{|c|}{ Death of self } \\
\hline 1 & .15619 & .23663 & .68939 & -.00183 \\
\hline 2 & .13289 & .51184 & .66175 & .04655 \\
\hline 3 & .11414 & .35701 & .73351 & .11881 \\
\hline 4 & .20089 & .55077 & .52548 & -.09213 \\
\hline 5 & .03041 & -.11544 & .76972 & .27550 \\
\hline 6 & .21516 & .09093 & .57887 & .31268 \\
\hline 7 & .44776 & -.28746 & .18467 & .20735 \\
\hline 8 & .15505 & -.07474 & .75059 & .36142 \\
\hline \multicolumn{5}{|c|}{ Dying of self } \\
\hline 9 & .68082 & .16094 & .32326 & -.11646 \\
\hline 10 & .68132 & .17506 & .24521 & .00568 \\
\hline 11 & .69521 & .14678 & -.01060 & .10097 \\
\hline 12 & .74101 & .14196 & .17482 & .14782 \\
\hline 13 & .42023 & .34085 & .26818 & .26303 \\
\hline 14 & .71644 & .25888 & .18561 & .16879 \\
\hline 15 & .47297 & .50242 & .15688 & .30115 \\
\hline 16 & .37573 & .48847 & -.00857 & -.03243 \\
\hline \multicolumn{5}{|c|}{ Death of others } \\
\hline 17 & .31806 & .63317 & .25478 & .08695 \\
\hline 18 & .18965 & .33097 & .25265 & .48606 \\
\hline 19 & .07989 & .57481 & .25418 & .40216 \\
\hline 20 & .15439 & .34504 & .02610 & .54346 \\
\hline 21 & .07169 & .69625 & .08894 & .22685 \\
\hline 22 & .00582 & .08644 & .04988 & .64557 \\
\hline 23 & .06926 & .68323 & .13426 & .16668 \\
\hline 24 & -.38978 & -.01590 & -.05118 & .34557 \\
\hline \multicolumn{5}{|c|}{ Dying of others } \\
\hline 25 & .06270 & .11467 & .27671 & .72747 \\
\hline 26 & .07328 & .04753 & .27665 & .76181 \\
\hline 27 & .39466 & .40082 & -.09906 & .29215 \\
\hline 28 & .42192 & .40315 & .02743 & .39789 \\
\hline 29 & .42897 & .35649 & .13581 & .49802 \\
\hline 30 & .24690 & .61368 & .09155 & .33619 \\
\hline 31 & .56381 & .30196 & -.12604 & .35331 \\
\hline 32 & .19557 & .32454 & .20016 & .52190 \\
\hline
\end{tabular}

With a sample size of 106 there is little evidence for a four-factor structure. Apart from the Death and Dying of self subscales the results provide little support for the content validity of the items in remaining sub-scales. 
To determine if a clearer result would be obtained with a larger sample size, data for Sample $2(n=493)$ were analyzed. Principal component analysis identified seven factors with eigenvalues equal to or greater than 1 (see Table 13). The first four factors accounted for $50.4 \%$ of the total variance, while the remaining three factors accounted for a further $10.6 \%$ of the total variance. Cattell's scree-test indicated more clearly than with the smaller sample a four-factor solution (see Figure 6).

Table 13

Principal Component Extraction ( $n=493)$

\begin{tabular}{|c|c|c|c|}
\hline Factor & Eigenvalue & $\begin{array}{l}\text { Percentage of } \\
\text { variance }\end{array}$ & $\begin{array}{l}\text { Cumulative } \\
\text { percentage }\end{array}$ \\
\hline 1 & 9.79216 & 30.6 & 30.6 \\
\hline 2 & 2.42369 & 7.6 & 38.2 \\
\hline 3 & 2.18541 & 6.8 & 45.0 \\
\hline 4 & 1.72644 & 5.4 & 50.4 \\
\hline 5 & 1.26346 & 3.9 & 54.3 \\
\hline 6 & 1.12537 & 3.5 & 57.9 \\
\hline 7 & 1.00384 & 3.1 & 61.0 \\
\hline 8 & .93096 & 2.9 & 63.9 \\
\hline 9 & .88215 & 2.8 & 66.7 \\
\hline 10 & .76030 & 2.4 & 69.0 \\
\hline 11 & .72625 & 2.3 & 71.3 \\
\hline 12 & .70920 & 2.2 & 73.5 \\
\hline 13 & .64061 & 2.0 & 75.5 \\
\hline 14 & .62167 & 1.9 & 77.5 \\
\hline 15 & .60403 & 1.9 & 79.4 \\
\hline 16 & .56469 & 1,8 & 81.1 \\
\hline 17 & .52202 & 1,6 & 82.8 \\
\hline 18 & .51594 & 1.6 & 84.4 \\
\hline 19 & .48039 & 1.5 & 85.9 \\
\hline 20 & .46127 & 1.4 & 87.3 \\
\hline 21 & .43403 & 1.4 & 88.7 \\
\hline 22 & .40608 & 1.3 & 89.9 \\
\hline 23 & .38085 & 1.2 & 91.1 \\
\hline 24 & .37369 & 1.2 & 92.3 \\
\hline 25 & .35730 & 1.1 & 93.4 \\
\hline 26 & .34511 & 1.1 & 94.5 \\
\hline 27 & .32706 & 1.0 & 95.5 \\
\hline 28 & .32219 & 1.0 & 96.5 \\
\hline 29 & .30715 & 1.0 & 97.5 \\
\hline 30 & .28975 & .9 & 98.4 \\
\hline 31 & .28068 & .9 & 99.3 \\
\hline 32 & .23623 & .7 & 100.0 \\
\hline
\end{tabular}




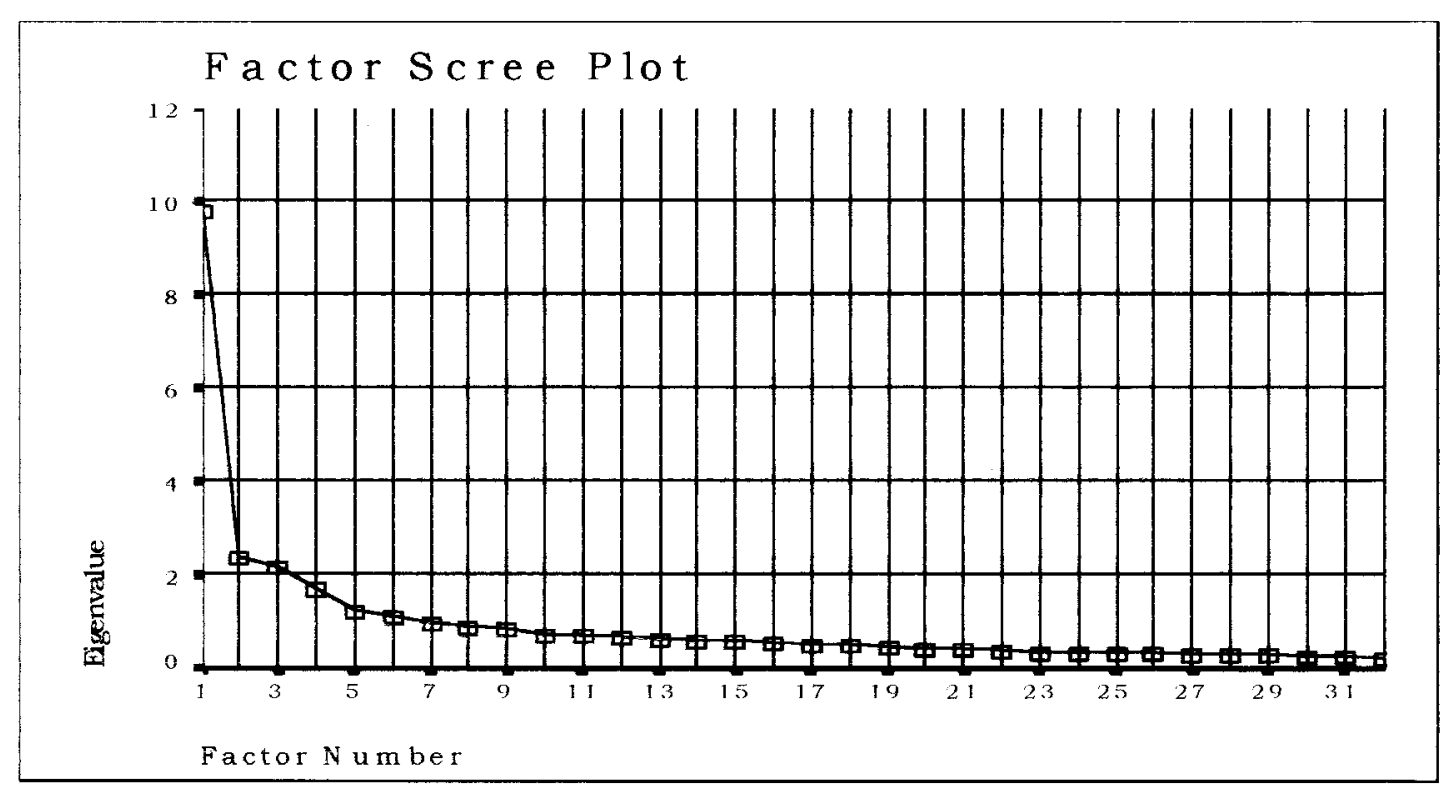

Figure 6. Scree plot for analysis of the increased sample size $(n=493)$.

Table 14 presents the unrotated four-factor solution and Table 15 the solution following Varimax rotation. Inspection of Table 15 indicates that Factor 1 had loadings $(>, 40)$ on items 9 to 16 in the Dying of self subscale with additional loadings on item 27, 29, and 31 in the Dying of others subscale. Factor 2 loaded on items 25, 27, 28, 29, 30, and 31 in the Dying of others subscale and items $17,18,19,21$, and 23 in the Death of others subscale. Factor 3 loaded on 7 of the 8 items in the Death of self subscale and Factor 4 loaded on items 20, 22, and 24 in the Death of others subscale, items 25, 26, and 32 in the Dying of others subscale, and item 7 in the Death of self subscale. Cross loading (at the $>.30$ level) is apparent, with item 25 loading on Factors 2 and 4, item 27, 29 and 31 loading on Factors 1 and 2. Overall, there is reasonable support for the Death (Factor 3) and Dying (Factor 1) of self subscales, and moderate support for the Dying of 
others subscale (Factor 2). The death of others subscale is not recognizable in the four factor solution. Alternatively Factor 2 could be described as a mix of the Death and Dying of others subscales.

Table 14

Principal Component Analysis - Unrotated Factor Matrix $(n=493)$

\begin{tabular}{|c|c|c|c|c|}
\hline & Factor 1 & Factor 2 & Factor 3 & Factor 4 \\
\hline \multicolumn{5}{|c|}{ Death of self } \\
\hline 1 & .57475 & -.43336 & .16771 & -.13056 \\
\hline 2 & .57239 & -.42807 & .12422 & -.29787 \\
\hline 3 & .58612 & -.41932 & .14837 & -.16339 \\
\hline 4 & .62078 & -.35963 & .01588 & -.24480 \\
\hline 5 & .53453 & -.36199 & .30909 & .07217 \\
\hline 6 & .58183 & -.32300 & .23995 & -.12472 \\
\hline 7 & .38701 & -.12899 & .17842 & .30358 \\
\hline 8 & .54604 & -.31786 & .27084 & .17611 \\
\hline \multicolumn{5}{|c|}{ Dying of self } \\
\hline 9 & .56114 & -.17258 & -.44223 & .15669 \\
\hline 10 & .64319 & -.14303 & -.32482 & .15310 \\
\hline 11 & .52166 & -.02759 & -.47380 & .16425 \\
\hline 12 & .61784 & -.08259 & -.40956 & .22782 \\
\hline 13 & .64741 & -.18126 & -.06410 & .23387 \\
\hline 14 & .70158 & -.20670 & -.24794 & .24521 \\
\hline 15 & .66703 & -.13435 & -.20790 & .02240 \\
\hline 16 & .47718 & -.00118 & -.36217 & -.01169 \\
\hline \multicolumn{5}{|c|}{ Death of others } \\
\hline 17 & .57552 & .17371 & -.04698 & -.41076 \\
\hline 18 & .46420 & .23134 & .33829 & -.08582 \\
\hline 19 & .56718 & .21247 & .15391 & -.39539 \\
\hline 20 & .48110 & .14955 & .34830 & .04606 \\
\hline 21 & .59637 & .21968 & .01856 & -.32431 \\
\hline 22 & .36981 & .10974 & .25074 & .43992 \\
\hline 23 & .56765 & .25212 & -.01172 & -.45057 \\
\hline 24 & .07279 & .16143 & .30635 & .45261 \\
\hline \multicolumn{5}{|c|}{ Dying of others } \\
\hline 25 & .51802 & .28810 & 40667 & .14660 \\
\hline 26 & .48017 & .26769 & .42285 & .21614 \\
\hline 27 & .51998 & .39242 & -.24792 & -.05530 \\
\hline 28 & .58880 & .36298 & -.03995 & .00923 \\
\hline 29 & .58739 & .43782 & -.14779 & .07901 \\
\hline 30 & .61972 & .33167 & .06534 & -.02465 \\
\hline 31 & .50113 & .42828 & -.22673 & .03605 \\
\hline 32 & .59220 & .12778 & .15620 & 14755 \\
\hline
\end{tabular}


Table 15

Principal Component Analysis with Orthogonal Rotation $(n=493)$

\begin{tabular}{|c|c|c|c|c|}
\hline & Factor 1 & Factor 2 & Factor 3 & Factor 4 \\
\hline \multicolumn{5}{|c|}{ Death of Self } \\
\hline 1 & .18889 & .12229 & .71021 & .09102 \\
\hline 2 & .15770 & .21361 & .73637 & -.04999 \\
\hline 3 & .19594 & .15430 & .70832 & .06455 \\
\hline 4 & .27696 & .24832 & .65942 & $=.04104$ \\
\hline 5 & .13056 & .04186 & .63048 & .31811 \\
\hline 6 & .13100 & .19643 & .65741 & .16749 \\
\hline 7 & .20878 & -.02645 & .27397 & .41433 \\
\hline 8 & .19949 & .01698 & .56226 & .38386 \\
\hline \multicolumn{5}{|c|}{ Dying of Self } \\
\hline 9 & .71279 & .08889 & .22091 & .00306 \\
\hline 10 & .66752 & .16076 & .28442 & .10383 \\
\hline 11 & .70293 & .15278 & .08186 & .01400 \\
\hline 12 & .73785 & .13947 & .17692 & .11406 \\
\hline 13 & .51486 & .10337 & .38029 & .30853 \\
\hline 14 & .68356 & .10634 & .36249 & .21582 \\
\hline 15 & .54513 & .25719 & .36772 & .09041 \\
\hline 16 & .52801 & .24744 & .12725 & -.05286 \\
\hline \multicolumn{5}{|c|}{ Death of Others } \\
\hline 17 & .18498 & .64712 & .27263 & -.07086 \\
\hline 18 & -.04612 & .46535 & .21689 & .35362 \\
\hline 19 & .03407 & .66942 & .30605 & .06246 \\
\hline 20 & .01274 & .35138 & .25210 & .43597 \\
\hline 21 & .17583 & .64371 & .24907 & .04605 \\
\hline 22 & .17297 & .04436 & .07937 & .60581 \\
\hline 23 & .13223 & .71593 & .23495 & -.06081 \\
\hline 24 & -.03330 & -.08970 & -.09767 & .55801 \\
\hline \multicolumn{5}{|c|}{ Dying of Others } \\
\hline 25 & .01407 & .40701 & .16333 & .58795 \\
\hline 26 & .00890 & .33621 & .14469 & .62745 \\
\hline 27 & .41318 & .54900 & -.08409 & .09858 \\
\hline 28 & .32472 & .54405 & .02806 & .27911 \\
\hline 29 & .42217 & .54659 & -.08405 & .28454 \\
\hline 30 & .25465 & .56551 & .11317 & .31858 \\
\hline 31 & .41750 & .51239 & -.13793 & .17718 \\
\hline 32 & .25597 & .33255 & .23075 & .42877 \\
\hline
\end{tabular}

Examination of the loadings for individual items suggests that some items are not functioning well in the subscales or the test as a whole. In view of these results, the item analysis was re-run, with results as shown in Table 16. In the cases where the Principal Components Analysis pointed to a problem with the item, the item analysis indicated that even though the item-correlation was not as high as those for other items in the subscale 
deletion of the item would in fact lower the internal consistency of the test.

Table 16

Reliability Analysis - Scale Alpha Item-total Statistics ( $n=493)$.

\begin{tabular}{|c|c|c|c|c|}
\hline Item & $\begin{array}{c}\text { Scale Mean if item } \\
\text { deleted }\end{array}$ & $\begin{array}{c}\text { Scale Variance if } \\
\text { item deleted }\end{array}$ & $\begin{array}{l}\text { Corrected item } \\
\text { total correlation }\end{array}$ & $\begin{array}{c}\text { Alpha if item } \\
\text { deleted }\end{array}$ \\
\hline \multicolumn{5}{|l|}{ Death of self } \\
\hline 1 & 19.1846 & 46.3419 & .6632 & .8224 \\
\hline 2 & 18.6897 & 47.4218 & .6280 & .8270 \\
\hline 3 & 18.9432 & 45.7732 & .6556 & .8230 \\
\hline 4 & 18.3428 & 47.1932 & .6011 & .8300 \\
\hline 5 & 19.4016 & 46.8099 & .6132 & .8285 \\
\hline 6 & 19.2414 & 45.9152 & .6365 & .8255 \\
\hline 7 & 19.7363 & 52.2759 & .3382 & .8601 \\
\hline 8 & 19.8641 & 48.9591 & .5705 & .8339 \\
\hline Alpha $=.8496$ & & & & \\
\hline \multicolumn{5}{|l|}{ Dying of self } \\
\hline 9 & 25.2698 & 38.5185 & .6302 & .8554 \\
\hline 10 & 25.3022 & 38.4552 & .6765 & .8508 \\
\hline 11 & 25.3164 & 39.8184 & .5658 & .8620 \\
\hline 12 & 25.5152 & 27.5877 & .6785 & .8500 \\
\hline 13 & 25.8824 & 37.8845 & .6184 & .8568 \\
\hline 14 & 25.6775 & 35.8897 & .7312 & .8435 \\
\hline 15 & 25.4868 & 37.3560 & .6310 & .8555 \\
\hline 16 & 25.0609 & 41.3865 & .4842 & .8696 \\
\hline \multicolumn{5}{|l|}{ Alpha $=.8714$} \\
\hline \multicolumn{5}{|l|}{ Death of others } \\
\hline 17 & 22.4381 & 28.4093 & .5150 & .7189 \\
\hline 18 & 23.6653 & 24.6662 & .4797 & .7170 \\
\hline 19 & 22.7546 & 25.8522 & .5612 & .7020 \\
\hline 20 & 23.8012 & 24.7734 & .5153 & .7084 \\
\hline 21 & 23.0791 & 25.2681 & .5648 & .6996 \\
\hline 22 & 24.4868 & 27.3926 & .3193 & .7486 \\
\hline 23 & 23.0588 & 25.9538 & .5128 & .7099 \\
\hline 24 & 25.2759 & 30.7855 & .1502 & .7687 \\
\hline \multicolumn{5}{|l|}{ Alpha $=.7490$} \\
\hline \multicolumn{5}{|l|}{ Dying of Others } \\
\hline 25 & 23.4990 & 31.7668 & .5539 & .8204 \\
\hline 26 & 23.8824 & 32.4048 & .5493 & .8207 \\
\hline 27 & 21.9939 & 33.6849 & .5435 & .8218 \\
\hline 28 & 22.2779 & 31.6889 & .5946 & .8148 \\
\hline 29 & 22.6755 & 31.1221 & .6709 & .8050 \\
\hline 30 & 22.6957 & 31.5576 & .6081 & .8130 \\
\hline 31 & 22.4483 & 33.2600 & .5422 & .8216 \\
\hline 32 & 23.2799 & 32.2508 & .4896 & .8298 \\
\hline Alpha $=.8375$ & & & & \\
\hline
\end{tabular}

Inspection of Table 16 indicates deletion of item 7 would raise the reliability 
coefficient for the Death of self subscale from .85 to .86 . Deletion of item 24 would raise the reliability coefficient for the Dying of others subscale from .75 to .77 .

\section{Discussion}

In this study the question of the factor-structure of the Collett-Lester scale was investigated. Initially a sample of 106 , similar to $\mathrm{Ns}$ in previous studies, was used to determine the adequacy of a four-factor solution. Four factors accounted for $54.2 \%$ of the total variance in this sample. Some cross loading was evident and little support for the hypothesized four subscales observed. These findings are similar to those reported by Lester (1990) who used a sample size of 73 , and found that the factor structure did not match the subscales he proposed in designing the scale.

When the sample was increased to 493 , four factors accounted for $50.4 \%$ of the total variance, but there was better recovery of the four subscales. The Death of self and Dying of self subscales could be identified with reasonable clarity. Items from the other two subscales, however, showed salient loadings on the one factor. That is, while the distinction between death and dying Lester sought to make in constructing his scale was recognizable for items relating to self, the distinction appeared to collapse for items relating to others. The clear two-way classification of death and dying and self and others on which the scale development was based was not recoverable in the factor analysis. 
There are several possible reasons for this failure to recover the four factors. One has to do with the techniques of analysis. The large sample size used here means that one obvious criticism of previous factor analytic work with the scale does not apply to the present study. Although not reported in detail here, variations in the method of analysis (use of a principal axis solution and oblique rotation of factors) did not materially alter the conclusions to be drawn, making these aspects of technique an unlikely explanation for the findings. The analysis strategy used was, however, an exploratory one and a confirmatory factor analysis may have provided support for a four-factor solution. A further possibility is that rewriting of some of the items, particularly Item $25,27,29$, and 31 that performed poorly and present some ambiguity in meaning, may improve recovery of the four subscales. Alternatively, the poor recovery of the two subscales relating to others may reflect differences in the semantic structures of the concepts of self and others. That is, finer distinctions may be made with respect to self, than can be made with respect to others. Finally, it could be argued that the large eigenvalue obtained for the first component in both analyses suggests unidimensionality of the scale.

In general the present study provided an equivocal answer to the question posed about the factor structure of the Collett-Lester scale, and as such provided only partial support for its construct validity. 


\section{Chapter 5}

\section{General Discussion}

The review of the literature in Chapter 1 confirms the numerous attempts that have been made to measure fear of death and death anxiety both as a unidimensional and a multidimensional construct, but equally that the psychometric adequacy particularly the construct validity of many of the instruments used in these studies has been lacking. The present project was undertaken to provide a surer base for the measurement of death anxiety than much of the research to date has provided. The starting point was the conclusions of Kastenbaum and Aisenberg (1972) with respect to the nature of death anxiety and the work of Collett and Lester that led to the 32-item version of the Collett-Lester Fear of Death and Dying Scale. Kastenbaum and Aisenberg's (1972) conclusions based on their review of several decades of research were that fear of death is normal and similar to other fears people experience in everyday life, is multifaceted, and is learned in the course of socialization. These conclusions led to the formulation of three broad research questions about the construct validity of the revised Collett-Lester scale.

The first question asked about the relationships between the scale and the Multidimensional Fear of Death Scale and broad dimensions of personality frequently studied in the literature, extraversion, neuroticism and social desirability and was examined in a sample of 106 participants. The pattern of relationships that emerged provided considerable support for the construct 
validity of the Collett-Lester scale. The subscales of the scale related to the Multidimensional Fear of Death scale, although not with the specificity predicted to neuroticism but not to extraversion or social desirability. This first study provided, as well, data on the internal consistency and test-retest stability of the scales. All four subscales were found to reach standards of reliability expected of research instruments.

The second question concerned the sensitivity of the scale: Would it measure changes in attitude at the conclusion 14-week program designed to alter attitudes towards death and dying? There were statistically significant differences in the expected direction for three of the four sub-scales between the experimental and comparison groups at posttest where none existed at pretest. The findings of a marginal increase in scores in the comparison group and the failure of the Death of self subscale to significantly decrease in score suggests that replication of certain aspects of this study should be undertaken before an unequivocal conclusion regarding construct validity can be reached.

The third and final question in the series concerned the factor structure of the test. Lester distinguished between fear of death and fear of dying with respect to both self and others and used this formulation to construct the four subscales of his instrument. Recovery of four factors that matched the four subscales from a factor analysis of the 32 items comprising the scale would provide strong support for the construct validity of the scale. Two of the four subscales were recognizable in an analysis using a sample of 493 
participants but the other two collapsed into the one factor. These results provided only limited support for the construct validity of the scale.

\section{Limitations of the Study.}

Although basic exploratory factor analytic procedures have been used in this research, a major weakness of this technique is the inability to determine goodness-of-fit of the resulting factor structure. Confirmatory factor analysis of the type recommended by Neimeyer and associates (Moore \& Neimeyer, 1991; Neimeyer, Moore, \& Bagley, 1988) using LISREL modeling would have allowed a more confident interpretation of the scale in question. Further, Study 2 would have been enhanced had a true experimental design been employed. It may also have produced more reliable results had a subset of the control group not been about to visit a human anatomy laboratory when the second testing took place. However, this situation was unforeseeable, as the Subject Convenor had not contemplated the visit at the time they were recruited. Finally, it must be admitted that a convenience sample of predominantly young, female undergraduate students enrolled in health related programs is not representative of the wider community, and work with different samples is needed to test the generality of the present findings.

\section{Suggestions for Further Research.}

In both studies 1 and 3 item analysis indicates that the scale would benefit from rewording or rewriting a number of items. Items 7 and 24 in particular emerged as poor items. Reworking a number of items in the subscales relating to anxiety for others may assist in bringing out Lester's original 
distinction. In fact, every question in the scale is couched in language more appropriate for earlier decades and consideration should also be given to revising the scale to reflect the language of the present generation. Up to half the questions in each subscale could be reworded and restructured to facilitate reverse scoring, to check whether there is any contribution of response bias.

Apart from extending the research by examining the difference in scale scores between such groups as police officers, firefighters, and mortuary workers, who by the nature of their work are exposed to situations which precipitate death anxiety, and control groups such as office or factory workers, and retail assistants who by the nature of their occupations would be unlikely to be exposed to situations which provoke death anxiety, consideration needs to be given to examining developmental changes in scores on the subscales. Little attention was paid in the present study to age (or gender) differences in death anxiety because of the nature of the sample employed. Lester has pointed to the dearth of information on the childhood experiences, family patterns, and parental behaviors that lead to death anxiety. The present study points to the value of the revised Collett-Lester Scale, with some modifications suggested by this project in beginning such an exploration of the development of death anxiety. 


\section{Reference List}

Abernathy, C. (1980). The effects of a short-term training program on community college counselors' attitudes towards aging and older adults. Unpublished Doctoral Dissertation. Virginia State University.

Abdel-Khalek, A. M. (1997). Two scales of death anxiety: Their reliability and correlation among Kuwaiti samples. Perception and Motor Skills. 84, (3) 921-922.

Aday, R. (1995). Elderly reactions to a death education program in a Nursing Home setting. Gerontology and Geriatric Education, 15, (3) 3-18.

Alexander, I., \& Alderstein, A. (1958). Affective responses to the concept of death in a population of children and early adolescents. Journal of Genetic Psychology, 93, 167-177.

Alexander, M., \& Lester, D. (1972). Fear of death in parachute jumpers. Perceptual \& Motor Skills, $\underline{34}, 338$.

Bailis. L. A., \& Kennedy, W.R. (1977). Effects of a death education program on secondary school students. Journal of Educational Research, $\underline{71}, 63-$ 66.

Behrens, T. T. (1993). Conveying thoughts, feelings, and fears: An Adlerian approach to addressing death. MF01/PCO1.

Bengtson, V. L., Cuellar, J., \& Ragan, P. (1977). Stratum contrasts and similarities in attitudes toward death. Journal of Gerontology, $\underline{32}, 76-88$.

Benvenutti, J. C. (1991). Attitudes of associate degree nursing students towards death and dying. Unpublished Doctoral Dissertation. University of Southern Mississippi. 
Bivens, A. J., Neimeyer, R. A., Kirchberg, T. M., \& Moore, M. K. (1995). Death concern and religious belief among gays and bisexuals of variable proximity to AIDS. Omega, $\underline{30}, 105-120$.

Bohart, J. B. (1976). The impact of death and dying counseling groups in death anxiety for college student volunteers. Unpublished Doctoral Dissertation. University of Colorado.

Bohart, J. B., \& Bergland, B. W. (1979). The impact of death and dying counseling groups on death anxiety in college students. Death Education, $\underline{2}, 381-391$.

Boyar, J. I. (1964). The construction and partial validation of a scale for the measurement of the fear of death. Dissertation Abstracts, $\underline{25}, 2041$.

Bugen, L. A. (1981) Coping: Effects of death education. Omega, 11, 175-183.

Campbell, D. T. \& Fiske, D. W. (1959). Convergent and discriminant validity by the multitrait-multimethod matrix. Psychological Bulletin, $\underline{56}$, (2). 81105.

Campbell, D. T., \& Stanley, J. C. (1966). Experimental and quasi-experimental designs for research. Chicago: Ranel McNally.

Carrera, R. N., \& Elenewski, J. J. (1980). Implosive therapy as a treatment for insomnia. Joumal of Clinical Psychology, 36, (3) 729-743.

Catania, J. A., Turner, H. A., Choi, K., \& Coates, T. J. (1992). Coping with death anxiety: Help seeking and social support among gay men with various HIV diagnoses. AIDS, $\underline{6}, 1037-1038$.

Cattell, R. B. (1966). The Scree test for the number of factors. Multivariate Behavioral Research.1, 245-276. 
Caty, S., \& Tamlyn, D. (1984). Positive effects on education on nursing students attitudes towards death and dying. Nursing Papers: Perspectives on Nursing, 16, 41-53.

Chen, J. (1992). An analysis of nurses attitude change towards dying as effected by death education. Unpublished Doctoral Dissertation. Drake University.

Cherulnik, P. D. (1983). Behavioural research: Assessing the validity of research findings in psychology. New York: Harper Row.

Chodil, J. J., \& Dulaney, P. E. (1984). Continuing education on dying and death. The Journal of Continuing Education in Nursing, 15, (1) 5-8.

Chui, S. (1995). Fear of Death: A descriptive pilot study of Medical and surgical Taiwanese Registered Nurses. Unpublished Master Thesis. Griffith University.

Coakes, S. J., \& Steed, L. G. (1997). SPSS Analysis without anguish. Brisbane: Jacaranda Wiley.

Cohen, R. J., \& Parker, C. (1974). Fear of failure and death. Psychological Reports, 34, (1) 54 .

Coleman, T. (1993). The effect of an instructional module on death and dying on the death anxiety of emergency medical technician trainees. Omega, $\underline{27}$, (2) 123-129.

Collett, L., \& Lester, D. (1969) The fear of death and dying. Journal of Psychology, 72, 179-181.

Combs, D. C. (1981). The effects of selected death education curriculum models on death anxiety and death acceptance. Death Education, $\underline{5},(1)$ 75-81. 
Conrad-Glass, J. (1990). Changing death anxiety through death education in the public schools. Death Studies, $14,31-52$

Crowne, D. P., \& Marlowe, D. (1960).A new scale of social desirability independent of psychopathology. Journal of Consulting Psychology, 24, (4) $349-354$.

Crowne, D. P., \& Marlowe, D. (1964). The approval motive: Studies in evaluative dependence. New York: John Wiley and Sons.

Davis-Berman, J. (1999). Attitudes toward aging and death anxiety: Aging and death class. Omega, $\underline{38}$, (1) 59-64.

D'Amanda, C., Plumb, M. M., \& Tantor, Z, (1977). Heroin addicts with a history of glue sniffing. International Journal of Addictions, $\underline{12}, 255-270$

Dattel, A. R., \& Neimeyer, R. A. (1990). Sex differences in death anxiety: Testing the emotional expressiveness hypothesis. Death Studies, 14, 1-11.

Derogatis, L. R., Lipman, R. S., Rickels, K., Uhlenhuth, E. H., \& Covi, L. (1974). The Hopkins Symptom Checklist: A measure of primary symptom dimensions. Psychological Measurement in Psychopharmacology, 7,79 110.

Depola, S., Neimeyer, R., Luper, M. \& Fielder, J. (1992). Death concern and attitude toward the elderly in nursing home personnel. Death Studies, 16 , 537-555.

Dickstein, L.D. (1972). Death concerns: Measurement and correlates. Psychological Reports, $\underline{30}, 563$.

Dickstein, L. D. (1975). Self-report and fantasy correlates of death concerns. Psychological Reports, 37, 147-158. 
Dickstein, L.D. (1978). Attitudes toward death, anxiety, and social desirability. Omega, $\underline{8}, 369-378$.

Dickstein, L. S., \& Blatt, S. J. (1966). Death concern, futurity, and anticipation. Journal of Consulting Psychology, $\underline{30}, 11-17$.

Dickinson, G. E., Sumner, E. D., \& Frederick, L. M. (1992). Death education in selected health professions. Death Education, 16, 281-289.

Dobratz, M. C. (1990). The life closure scale: A measure of psychological adaptation in death and dying. The Hospice Journal, 6, (3) 1-15.

Donovan, J. M. (1993). Validation of a Portuguese form of Templer's Death Anxiety Scale. Psychological Report, 73, (1) 195-200.

Durlak, J. A. (1972). Measurement of the fear of death: An examination of some existing scales. Journal of Clinical Psychology, 28, 545-547.

Durlak. J. A. (1979). Comparison between experimental and didactic methods of death education. Omega, $\underline{9}$, (1) 57-66.

Durlak, J. A. (1982). Using the Templer scale to assess death anxiety: A cautionary note. Psychological Reports, 50, 1257-1258.

Durlak, J. A., \& Burchard, J. A. (1977). Preliminary evaluation of a hospitalbased continuing education workshop on death and dying. Journal of Medical Education, $\underline{52}$, 423-424.

Durlak, J. A., \& Kass, R. A. (1982). Clarifying the measurement of death attitudes. Omega, 12, 129-141.

Durlak, J. A., \& Kasimatis, M. R. (1989). Convergent and discriminant validity of self-report death scales. Omega, $\underline{19}$, (2) 163-174. 
Durlak, J. A., \& Riesenberg, L. A. (1991). The impact of death education. Death Studies, 15 , 39-58.

Durkheim, E. (1897). Le Suicide. Paris: Felix Alcan.

Eysenck, H. J. (1958). A short questionnaire for the measurement of two dimensions of personality. Journal of Applied Psychology, 42, (1) 14-17.

Fang, B., \& Howell, K. A. (1976). Death anxiety among graduate students. Journal of the American College Health Administration, 25, 310-313.

Feifel, H. (1955). Attitudes of mentally ill persons toward death. Journal of Nervous and Mental Disease, 122, 375-380.

Feifel, H., \& Branscomb, A. B. (1973). Who's afraid of death? Journal of Abnormal Psychology, 1, 282-288.

Feifel, H., \& Nagy, V. T. (1981). Another look at fear of death. Journal of Consulting and Clinical Psychology, $\underline{49}$, (2) 278-286.

Florian, V, \& Har-Even, D. (1983). Fear of personal death: The effects of sex and religious belief. Omega, 14, 83-91.

Florian, V., \& Kravetz, S. (1983). Fear of personal death: Attribution, structure, and relation to religious belief. Journal of Personality and Social Psychology, 44, 600-607.

Florian, V. \& Mikulincer, M. (1997). Fear of personal death in adulthood: The impact of early and recent losses. Death Studies, 21, 1-24.

Florian, V., \& Snowden, L. (1988). Fear of personal death and positive life regard: $\Lambda$ study of different ethnic and religious-affiliated American college students. Journal of Cross-Cultural Psychology, 20, 64-79.

Ford, R. E., Alexander, M., \& Lester, D. (1971). Fear of death of those in a high stress occupation. Psychological Reports, $\underline{29}, 502$. 
Frazier, P. H., \& Foss-Goodman, D. (1989). Death anxiety and personality: Are they truly related? Omega, 19, (3) 265-274.

Fretz, B., \& Leviton, D., (1979). Life and death attitudes of parents of mildly dysfunctional children. Omega, $\underline{6}, 161-170$.

Gilliland, J. C., \& Templer, D. I. (1985). Relationship of Death Anxiety Scale factors to subjective states. Omega, $\underline{16}, 155-167$.

Glass, J. C. (1990). Changing death anxiety through education in Public Schools. Death Studies, $\underline{14}, 31-52$.

Glass, J. C., \& Knott. E. S. (1984). Effectiveness of a lesson on death and dying in changing adolescents death anxiety and attitudes towards older adults. Death Education, $\underline{8}, 299-313$.

Gomez, G. E., Young, E. A., \& Gomez, E. A. (1991). Attitude toward the elderly, fear of death, and work preference of baccalaureate nursing students. Gerontology and Geriatrics Education, 11, (4) 45-56.

Gordon, S., \& Hallauer, D. (1976). Impact of a friendly visiting program on attitudes of college students towards the aged, Gerontologist, $28,370-373$.

Gregory, R. J. (1996). Psychological testing: History, principles, and applications. (2nd ed.) Boston: Allyn and Bacon.

Gustavson, N. (1988). The effect of human dissection on first-year students and implications for the doctor-patient relationship. Journal of Medical Education, $\underline{63}, 62-64$.

Hall, G. S. (1896). Study of fears. American Journal of Psychology, $\underline{8}, 147$ 149. 
Handal, P., \& Rychlak, J. (1971). Curvilinearity between dream content and death anxiety and the relationship of death anxiety to repressionsensitization. Journal of Abnormal Psychology, 구, 11-16.

Hardt, D. V. (1980). A measurement of the improvement of attitudes towards death. Journal of School Health, $\underline{46}, 269-270$.

Hart, E. J. (1979). The effects of death anxiety and mode of 'case study' presentation on shifts of attitude toward euthanasia. Omega, $\underline{9}_{2}(3)$ 239-244.

Hayslip, B. (1987). The measurement of communication apprehension regarding the terminally ill. Omega, 17, 251-261.

Hayslip, B., Galt, C. P., \& Pinder, M. M. (1994). Effects of death education on conscious and unconscious death anxiety. Omega, $\underline{28}$, (2) 101-111.

Hayslip, B., \& Stewart-Bussey, D. (1987). Locus of control - levels of death anxiety. Omega, 17, 41-50.

Hayslip, B., \& Walling. M. L. (1986). Impact of hospice volunteer training on death anxiety and locus of control. Omega, 16, 243-254.

Hendricks, J., Mooney, R., \& Berry, C. (1996). A practical strategy approach to the use of a reflective practice in Critical Care Nursing. Intensive and Critical Care Nursing, 12, 97-101.

Hinkin, T. R., Tracey, B. J., \& Enz, C. (1997). Scale construction: Developing reliable and valid measuring instruments. Joumal of Hospitality \& Tourism Research, 21, (1) 101-120.

Hintze, J., Templer, D. I., Cappelletty, G. C., \& Frederick, W. (1993). Death depression and death anxiety in HIV-infected males. Death Studies, 17, 333-341. 
Ho, S. M., \& Shui, W. C. (1995). Death anxiety and coping mechanisms of Chinese cancer patients. Omega, $\underline{31}$, 59-65.

Hoelter, J. W. (1979). Multidimension treatment of fear of death. Journal of Consulting and Clinical Psychology, 47, 996-999.

Hoelter, J. W., \& Hoelter, J. A. (1980). On the interrelationships among exposure to death and dying, fear of death, and anxiety. Omega, $\underline{7}, 241-$ 254.

Hoelter, J. W., Whitlock, S., \& Epley, R. J. (1979).Death education and death related studies. Death Education, $\underline{3}, 67-75$.

Howells, K., \& Field, D. (1982). Fear of death and dying among medical students. Social Science $\&$ Medicine, $\underline{16}, 1421-1424$.

Hunt, D. M., Lester, D., \& Ashton, N. (1983). Fear of death, locus of control and occupation. Psychological Reports, 푸, 1002.

Hurtig, A. W., \& Stewin, L. (1990). The effect of death education and experience on nursing students' attitude toward death. Journal Advanced Nursing, 15, 29-34.

Johansson, N., \& Lally, T. (1991). Effectiveness of a death education program in reducing death anxiety of nursing students. Omega, 22 (1) 25-33.

Johns, C. (1993). On becoming therapeutic through reflection. Paper presented to the British Nursing Development Unit Conference. Luton.

Jordan, T. J., Ellis, R. R., \& Grallo, R. (1986). A comparison of levels of anxiety of medical students and graduate counselors about death. Journal of Medical Education, 61, 923-925.

Kachigan, K. (1986). Statistical analysis: An interdisciplinary introduction to univariate and multivariate methods. New York: Radius Press 
Kalish, R. (1986). Cemetery visits. Death Studies, 10, 55-58.

Kao, S., \& Lusk, B. (1997). Attitudes of Asian and American graduate nursing students towards death and dying. International Journal of Nursing Studies, $\underline{34},(6)$ 438-443.

Kastenbaum, R., \& Aisenberg, R. B. (1972). The psychology of death. (2nd ed.). New York :Springer.

Kastenbaum, R., \& Costa, P. T. (1977). Psychological perspectives on death. Annual Review of Psychology, 28, 225-249.

Kaye, J. M. (1991). Will a course on death and dying lower students' death and dying anxiety? Journal of Cancer Nursing, $\underline{6}$, (1) 21-24.

Kaye, J. M., Gracely, E., \& Loscalzo, G. (1994). Changes in students attitudes following a course on death and dying: A controlled comparison. Joumal of Cancer Education, $\underline{9}$, (2) 77-81.

Kaye, J. M., \& Loscalzo, G. (1998). Learning to care for dying patients: A controlled longitudinal study of a death education course. Journal of Cancer Education, 13, (1) 52-57.

Kelly, G. A. (1955). The Psychology of Personal Constructs. New York: Norton.

Kienow, N. L. (1992). Death education and death anxiety in student nurse aides. Unpublished Doctoral Dissertation. Washington State University.

Klug, L. F., \& Boss, M. (1976). Factorial structure of the death concern scale. Psychological Reports, 38, (1) 107-112.

Knight, K. H. (1993). Relationship of death education to the anxiety, fear, and meaning associated with death. Death Studies, 17, (5) 411-425. 
Knight, K. H., \& Elfenbein, M. H. (1993). Relationship of death education to anxiety, fear, and meaning associated with death. Death Studies, 17, 411425.

Kraft, W. A., Litwin, W. J., \& Barber, S. E. (1987). Religious orientation and assertiveness. Journal of Social Psychology, 127, 93-95.

Krieger, S. R., Epting, F. R., \& Leitner, L. M. (1974). Personal constructs, threat, and attitudes toward death, Omega, $\underline{5}, 299-310$.

Kurlychek, R.T. (1976). Level of belief in afterlife and four categories of fear

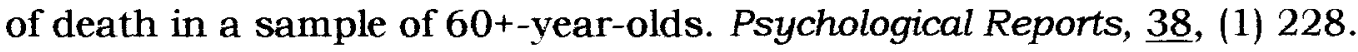

Kurlychek, R. T. (1978). Assessment of attitudes towards death and dying: A critical review of some available methods. Omega, 18, (13) 229-235.

Kurlychek, R.T., \& Trepper, T. S. (1982). Accuracy of perception of attitude. Perceptual \& Motor Skills, $\underline{54}, 272-274$.

Lan, Y. H. (1995). Nursing students caring for dying patients: Their fear of death, death attitudes, individual needs, coping and coping behaviours. Journal of Nursing (R.O.C.), $\underline{42}$, (1) 75-90.

Larrabee, M. J. (1978). Measuring fear of death: A reliability study. The Journal of Psychology, 100, 33-37.

Lattanner, B., 86 Hayslip, B. (1985). Occupational differences in level of death anxiety. Omega, 15, 53-66.

Laube, J. (1977). Death and dying workshop for nurses: Its effect on their death anxiety level. International journal of Nursing Studies, 14, 111-120.

Lester, D. (1967). Experimental and Correlational studies of the fear of death. Psychological Bulletin, 67, 27-36. 
Lester, D. (1969). Fear of death and the nightmare experience. Psychological Reports, 25, 437-438.

Lester, D. (1970a). Correlates of animism in adults, Psychological Reports, $\underline{27}, 806$.

Lester, D. (1970b). Relation of fear of death in subjects to fear of death in their parents. Psychological Record, 20, 541-543.

Lester, D. (1970c). Religious behavior and the fear of death. Omega, $1,181-$ 188.

Lester, D. (1971a). Attitudes towards death held by staff of a suicide prevention Centre. Psychological Reports, 28, 650.

Lester, D. (1971b).Attitudes towards death and suicide in a non-disturbed population. Psychological Reports, 29, 386.

Lester, D. (1972). Studies in death studies. Psychological Reports, $\underline{30}, 440$.

Lester, D. (1974). The Collett-Lester Fear of Death Scale: A Manual. Pomona: Richard Stockton State College.

Lester, D. (1979). Preference for method of suicide and attitudes towards death in normal people. Psychological Reports, $\underline{45}, 638$.

Lester, D. (1985 a). The fear of death, sex and androgyny. Omega, 15, 271274.

Lester, D. (1985 b). Depression and fear in a normal group. Psychological Reports, $\underline{56}, 882$.

Lester, D. (1990). The Collett-Lester fear of death scale: The original version and a revision. Death Studies, $14,451-468$.

Lester, D. (1991). Psychotherapy for suicidal clients. Springfield: Charles Thomas. 
Lester, D. (1994). The Collett-Lester Fear of Death Scale. In R. A. Neimeyer (Ed.), Death anxiety handbook: Research, instrumentation, and application. (pp.45-60). Philadelphia: Taylor \& Francis.

Lester, D., \& Blustien, J. (1980). Attitudes towards funerals. Psychological Reports. $\underline{46}, 1074$.

Lester, D., \& Castromayor, I. (1993). The construct validity of Templer's death anxiety scale in Filipino students. Joumal of Social Psychology, $\underline{133}$, (1) 113-114.

Lester, D., \& Collett, L. J. (1970). Fear of death and self-ideal discrepancy. Archives of the Foundation of Thanatology, $\underline{2}, 130$.

Lester, D., \& Colvin, L. M. (1977). Fear of death, alienation and selfactualization. Psychological Reports, $\underline{41}, 526$.

Lester, D., Getty, C., \& Kneisl, C. R. (1974). Attitudes of nursing students and faculty toward death. Nursing Research, 23, 50-53.

Lester, D., \& Templer, D. (1993). Death anxiety scales: A dialogue. Omega, 26, (4)239-253.

Lester, G., \& Lester, D. (1970). The fear of death, the fear of dying, and threshold differences for death words and neutral words. Omega, $\underline{1}, 175$ 179.

Lev, E. L. (1986). Effects of course in hospice nursing: Attitudes and behaviors of Baccalaureate School nursing undergraduates and graduates. Psychological Reports, $\underline{59}, 847-858$.

Leviton, D. \& Fretz, B. (1979). Effects of death education on fear of death and attitudes towards death and life. Omega, $\underline{9}$, (3) 267-277. 
Linn, M. W., Linn, B. S., \& Stein, S. (1983). Impact on nursing home staff of training about death and dying. JAMA, 250, (17) 2331-2335.

Linn, B. S., Moravec, J., \& Zeppa, R. (1982). The impact of clinical experience on attitudes of junior medical students about death and dying. Joumal of Medical Education, 57, (9) 684-691.

Livneh, H. (1985a). Brief note of the structure of the Collett-Lester fear of death scale. Psychological Reports, $\underline{56}, 136-138$.

Livneh, H. (1985b). Death attitudes and their relationship to perceptions of physically disabled persons. Journal of Rehabilitation, $\underline{51}$, 41-80.

Lockard, B. E. (1989). Immediate, residual and long-term effects of a death education instructional unit on the death anxiety of level of nursing students. Death Studies, $\underline{13},(2) 137-159$.

Lonetto, R., Flemming, S., \& Mercer, G. W. (1979). The structure of death anxiety: A factor analytic study. Joumal of Personality Assessment, 43 , 388-392.

Long, D. D. (1986). A cross cultural examination of fears of death among Saudi Arabians. Omega. 16, 43-50.

Loo, R. (1984, a). Personality and correlates of the fear of death. Journal of Clinical Psychology, 40, 120-122.

Loo, R. (1984, b) Correlates of reported attitudes towards and use of seatbelts. Accident Analysis and Prevention, 16, 417-421.

Loo, R, \& Shea, L. (1996). Structure of the Collett-Lester Fear of Death and Dying Scale. Death Studies, 20, (6) 577-586.

Madfes, I. S. (1995). Death anxiety and related characteristics among hospice and nonhospice nurses. 
Mansfield, D., Privette, G., \& Bilbrey, J. (1982). Effects of death education on students. The School Counselor, 29 , 322-327.

Marlowe, D., \& Crowne, D. P. (1961). Social desirability and response to perceived situational demands. Journal of Consulting Psychology, 25, (2) $109-115$

Martin, T. O. (1983). Death anxiety and social desirability among nurses. Omega, 13, (1) 51-58.

McDonald, R. T. (1981). The effects of death education on specific attitudes towards death in college students. Death Education, $\underline{5}$, (1) 59-65.

McDonald, R. T., \& Hilgendorf, W A. (1986). Death imagery and death anxiety. Journal of Clinical Psychology, $\underline{42}, 87-89$.

McNeil, J. N. (1983). Young mothers communicating about death with their children. Death Education, $\underline{6}, 323-339$.

Mikulincer, M., \& Florian, V. (1995). Stress coping and fear of personal death: The case for middle age men facing early job retirement. Death Studies, $\underline{19}, 413-431$.

Miles, M. S. (1980). The effects of a curse on death education on death and grief on nurses' attitudes towards dying patients and death. Death Education, $\underline{4}, 245-260$.

Molnar-Stickels, L. A. (1985). Impact of a brief instructional unit in death education on the death attitudes of prospective Elementary School Teachers. Journal of School Health, 55, (6) 234-236.

Mooney, D. C. (1998). End of life studies. Brisbane: Uniprint - Griffith University. 
Moore, M. K., \& Neimeyer, R. A. (1991). A confirmatory factor analysis of the threat index. Journal of Personality and Social Psychology, 60, 122-129.

Mueller, M. L. (1975). Fear of death and death education. Notre Dame Joumal of Education, $\underline{6}, 84-91$.

Mullins, L., \& Merriam, S. (1983). An experimental study of the impact of a short-term training program in death on nursing home nurses. Gerontology and Geriatrics Education, $\underline{3}, 213-221$.

Murphy, P. (1986). Reduction in nurse's death anxiety following a death awareness workshop, The Journal of Continuing Education in Nursing, 17 , (4) $115-118$.

Murray, P. (1974). Death education and its effects on the anxiety level of nurses. Psychological Reports, 35, 1250.

Murray-Frommelt, K. H. (1991). The effects of death education on nurse's attitudes toward caring for terminally ill persons and their families. The American Journal of Hospice and Palliative Care. 10, 37-43.

Nanda, S. (1994). Death from a cross: a cultural perspective In B. A. Barber, N. Hannon, \& N. A. Russel (Eds.). Death and dying: Understanding and care.(pp.313-337). New York: Hemisphere.

Nash, M., Connors, C., \& Gemperle, R. (1977). Towards dignity in care: An inservice model. Death Education, 1, 113-130.

Nehrke, M. (1973). Perceived generational differences in attitudes toward death. Paper presented at the 26th annual scientific meeting of the Gerontological Society, Miami Beach Florida. 
Nehrke, M.F., Bellucci, G., \& Gabriel, S. J. (1978). Death anxiety, locus of control, and life satisfaction in the elderly: Toward a definition of egointegrity. Omega, $\underline{8}, 359-368$.

Nehrke, M.F., Morganti, J. B. Willrich, R., \& Hulicka, I. M. (1979). Health status, room size, and activity level: Research in an institutional setting. Environment and Behavior, 11, 451-463.

Neimeyer, R. A. (1998a). Special article: Death anxiety research: State of the art. Omega, $\underline{36},(2)$ 97-120.

Neimeyer, R. A. (1988 b). Death Anxiety. In H. Wass, F. Berardo \& R. A. Neimeyer (Eds.) Dying: Facing the facts (pp. 97-136). New York: Hemisphere

Neimeyer, R. A. (1994). Death Anxiety Handbook: Research, instrumentation and application. New York: Taylor and Francis.

Neimeyer, R. A. (1998). Death anxiety research: The state of the art. Omega. 36, (2) $97-120$.

Neimeyer, R. A., Bagley, K., \& Moore, M. K. (1986). Cognitive structure and death anxiety. Death Studies, $\underline{10}$, 273-288.

Neimeyer, R. A., \& Chapman, K. M. (1980). Self/ideal discrepancy and fear of death: The test of an Existential Hypothesis. Omega, 11, (3) 233-240.

Neimeyer, R. A., \& Dingemans, P. M. (1981). Death orientation in the suicide intervention worker. Omega, 11, (1) 15-23.

Neimeyer, R. A., \& Epting, F. R. (1992). Measuring personal meanings of death: Twenty years of research using the Threat Index. In R. A. Neimeyer \& G. J. Neimeyer (Eds.). Advances in personal construct psychology. Greenwich: JAI Press. 
Neimeyer, R. A., Epting, F. R., \& Rigdon, M. A. (1984). A procedure manual for the threat index. In F. R. Epting \& R. A. Neimeyer (Eds.), Personal meanings in death Washington, D. C.: Hemisphere.

Neimeyer, R. A., \& Fortner, B. (1997). Death attitudes in contemporary perspective. In S. Strack (Ed.). Death and the quest for meaning. (pp. 329). Northvale: Jason Aronson.

Neimeyer, R. A., \& Moore, M. K. (1989). Assessing personal measures of death: Empirical refinements of the Threat Index. Death Studies, 13, 227245.

Neimeyer, R. A., Moore, M. K., \& Bagley, K. J. (1988). A preliminary factor structure for the Threat Index. Death Studies, 12, 217-225.

Neimeyer, R. A., \& Van Brunt, D. (1995). Death Anxiety. In H. Wass \& R. A. Neimeyer (Eds.) Dying: Facing the facts (3rd ed.). (pp. 49-88). New York: Taylor and Francis..

Nelson, L. D. (1978). The multidimensional measurement of death attitudes: Construction and validity of a three - factor instrument. The Psychological Record, 28, (4) 525-533.

Nelson, L. D. \& Nelson, C. C. (1975). A factor analytic inquiry into the multidimensionality of death anxiety. Omega, $\underline{6}, 171-178$.

Noland, M., Richardson, G. E., \& Bray, R. M. (1980). The systematic development and efficacy of a death education unit for ninth-grade girls. Death Education, 4 , 43-59.

Nunnally, J. C., \& Bernstein, I. H. (1994). Psychometric Theory. (3rd ed.) New York: McGraw-Hill.

Peterson, S. A. (1986). Death anxiety and politics. Omega, 16, 169-174. 
Polit, D. F. \& Hungler, B. P. (1997) Essentials of nursing research:

Methods, appraisal \& utilization. (4th ed.) Philadelphia. Lippincott.

Reaves, C. C. (1992). Quantitative research for the behavioural sciences. New York: John Wiley.

Rigdon, M. A., \& Epting, F. R. (1985). Reduction in death threat as a basis for optimal functioning. Death Studies, 9 , (5-6) 427-448.

Rigdon, M. A., Epting, F. R., Neimeyer, R. A., \& Krieger, S. R. (1979). The Threat Index. Death Education. $\underline{3}, 245-270$.

Roberts, C. A., \& Burke, S. O. (1989). Nursing research: A quantitative and qualitative approach. Boston: Jones \& Bartlett.

Robbins, R. A. (1989). Gender, and sex-role stereotypes in scales of death concern. Death studies, 13, (6) 579-591.

Robbins, R. A. (1991). Bugen's coping with death scale: Reliability and further validation. Omega, 22 , (4) 287-299.

Robinson, P. J., \& Wood, K. (1983). Fear of death and physical illness. Death Education, 7, 213-228.

Robinson, P. J., \& Wood, K. (1984). The Threat Index: An additive approach. Omega, 15, (2) 139-144.

Rosenthal, N. R. (1980). Adolescent death anxiety: The effect of death education. Education, 101, (1) 95-101.

Rublee, D., \& Yarber, W. (1983). Instructional units of death education: The impact of amount of classroom time on changes in death attitudes. Journal of School Health, 51, (10) 646-650.

Saggino, A., \& Kline, P. (1996). Item factor analysis of the Italian version of the death anxiety scale. Journal of Clinical Psychology, 52, (3) 329-333. 
Schachter, S. (1979). Death and dying education in a medical school curriculum, Journal of Medical Education, 54, 661-663.

Schell, B. H., \& Zinger, J. T. (1984). Death anxiety scale means and standard deviations for Ontario undergraduates and funeral directors. Psychological Reports, $\underline{44}$, 975-980.

Schultz, C. M. (1977). Death anxiety and the structuring of a death concerns cognitive domain. Essence, 1, 171-188.

Schulz, R. (1978). The psychology of death, dying and bereavement. Reading: Addison-Wesley

Scott, C. A. (1896). Old age and death. American Journal of Psychology, $\underline{8}$, $550-613$.

Shoemaker, R. K. (1981). The effects of a death education course on participant's attitude towards death and dying. Teaching of Psychology, $\underline{8}$, (4) 217-219.

Schumaker, J. F., Warren, W. G., \& Groth-Marnat, G. (1991). Death anxiety in Japan and Australia. Journal of Social Psychology, 131, (4) 511-518.

Shaughnessy, J. J., \& Zechmeister, E. B. (1994). Research methods in Psychology. (3rd ed.). New York: McGraw-Hill.

Slezak, M. E. (1982). Attitudes towards euthanasia as a function of death fears and demographic variables. Essence, $\underline{5}$, (3) 191-197.

Smith, D. K., Nehemkis, A. M., \& Charter, R. A. (1984). Fear of death, death attitudes and religious conviction in the terminally ill. International Journal of Psychiatry in Medicine, 13, 221-232.

Stroop, J. R. (1938). Factors affecting speed in serial verbal reactions. Psychological Monographs, $\underline{50}, 38-48$. 
Stoller, E. P. (1981). The impact of death-related fears on attitudes of nurses in hospital work settings. Omega, $\underline{11}$, 85-96.

Sundin, R. H., Gaines, W. G., \& Knapp, W. B. (1979). Attitudes of dental and medical students toward death and dying. Omega, 10, (1) 77-86.

Templer, D. I. (1970). The construction and validation of a death anxiety scale. The Journal of General Psychology, 82, 165-177.

Templer, D. I. (1976). Two factor theory of death anxiety. Essence, 2, 91-94.

Templer, D. I., Lester, D., \&, Ruff, C. F. (1974). Fear of death and femininity. Psychological Reports, $\underline{35}, 530$.

Terry, M. L., Bivens, A. J., \& Neimeyer, R. A. (1996). Comfort and empathy of experienced counselors in client situations involving death and loss. Omega, $\underline{32}$, 269-286.

Testa, J. R. (1981). Group systematic desensitization and implosive therapy for death anxiety. Psychological Reports, $\underline{48}, 376-378$.

Thorson, J. A., \& Powell, F. C. (1994). ‘A revised death anxiety scale'. In R. A. Neimeyer, (Ed.). Death anxiety handbook: Research, Instrumentation, and application. (pp. 31-43). Washington: Taylor and Francis.

Trent, C., \& Glass, C. (1980). Changing ninth-graders attitudes towards older persons, Research on the Aged, $\underline{2}, 499-512$.

Trent, C., Glass, J. C., \& McGee, A. (1981). The impact of a workshop on death and dying on death anxiety, life satisfaction, and locus of control among middle-aged and older adults, Death Education, $\underline{5}, 157-173$.

Triplett, G., Choen, D., Reimer, W., Rinaldi, S., Hill., Roshdieh., Stanczak, E. M. Siscoe, K \& Templer, D. I. (1995). Death discomfort differential. Omega, 31, (4) 295-304. 
Ungar, L., Florian, V., \&6 Zernitsky-Shurka, E. (1990). Aspects of fear of personal death, levels of awareness, and professional affiliation among dialysis unit staff members. Omega, 21, (1) 51-67.

Vandercreek, L., Frankowski, D., \& Ayres, S. (1994). Use of the Threat Index with family members waiting surgery. Death Studies, 18 , (6) 641-648.

Vargo, M. (1980). Relationship between the Templer Death Anxiety Scale and the Collett-Lester Fear of Death Scale. Psychological Reports, 46, (2) 561562.

Vargo, M. E., \& Batsel, W. M. (1984). The reduction of death anxiety: A comparison of didactic, experiential, and non-conscious treatments. British Journal of Medical Psychology, 57, 333-337.

Vickio, C. J., \& Cavanaugh, J. C. (1985). Relationships among death anxiety, attitudes towards aging, and experience with death in nursing homes employees. Journal of Gerontology, $\underline{40}, 347$ - 349.

Walkey, F. H. (1982). The multidimensional fear of death scale: An independent analysis. Journal of Consulting and Clinical Psychology, $\underline{50}$, 466-467.

Waltz, C. F., Strickland, O. L., \& Lenz, E. R. (1991). Measurement in nursing research (2nd ed.) Philadelphia: F. A. Davis

Warren, W. G., \& Chopra, P. N. (1978). Some reliability and validity considerations on Australian data from the death anxiety scale. Omega, 9, 293-299.

Wass, N., Richarde, S., Angenendt, S., Fitch, M., Drake, D., \& Stergios, J. (1980). Effectiveness of short-term death education programmes for adults. Essence, $\underline{4},(2)$ 49-55. 
Watts, P. (1977). Evaluation of death attitude change resulting from a death educational instructional unit, Death Education, 1, 187-193.

Wahl, C. (1958). The fear of death. Menninger Clinic Bulletin, 22, $214-223$.

Whelan, W., \& Warren, W. A. (1980). A death awareness workshop: Theory, application and results, Death Education, 1, 187-193.

Wear, D. (1989). Cadaver talk: Medical students' accounts of their year -long experience. Death Studies, 13, 379- 391.

Westman, A. S., \& Brackney, B. E. (1990). Relationships between indices of neuroticism, attitudes toward and concepts of death, and religiosity. Psychological Reports, 66, 1039 - 1043.

Wittmaier, B. (1979). Some unexpected attitudinal consequences of a short course on death. Omega, $\underline{10}, 271-275$.

Yarber, W. L., Gobel, P., \& Rublee, D. A. (1981). Effects of death education on nursing students anxiety and locus of control. Joumal of School Health, $\underline{51}, 367-372$.

Yeaworth, R. C., Kapp, F. T., \& Winget, C. (1974). Attitudes of nursing students toward the dying patient. Nursing Research, 23, (1) 20-24.

Yates, P., Clinton, M., \& Hart, G. (1996). Improving psychosocial care: A professional development programme. International Journal of Palliative Nursing, 2, (4) 212-216. 
Appendix A

Researchers Who Have Used Collett-Lester Fear of Death and Dying Scale.

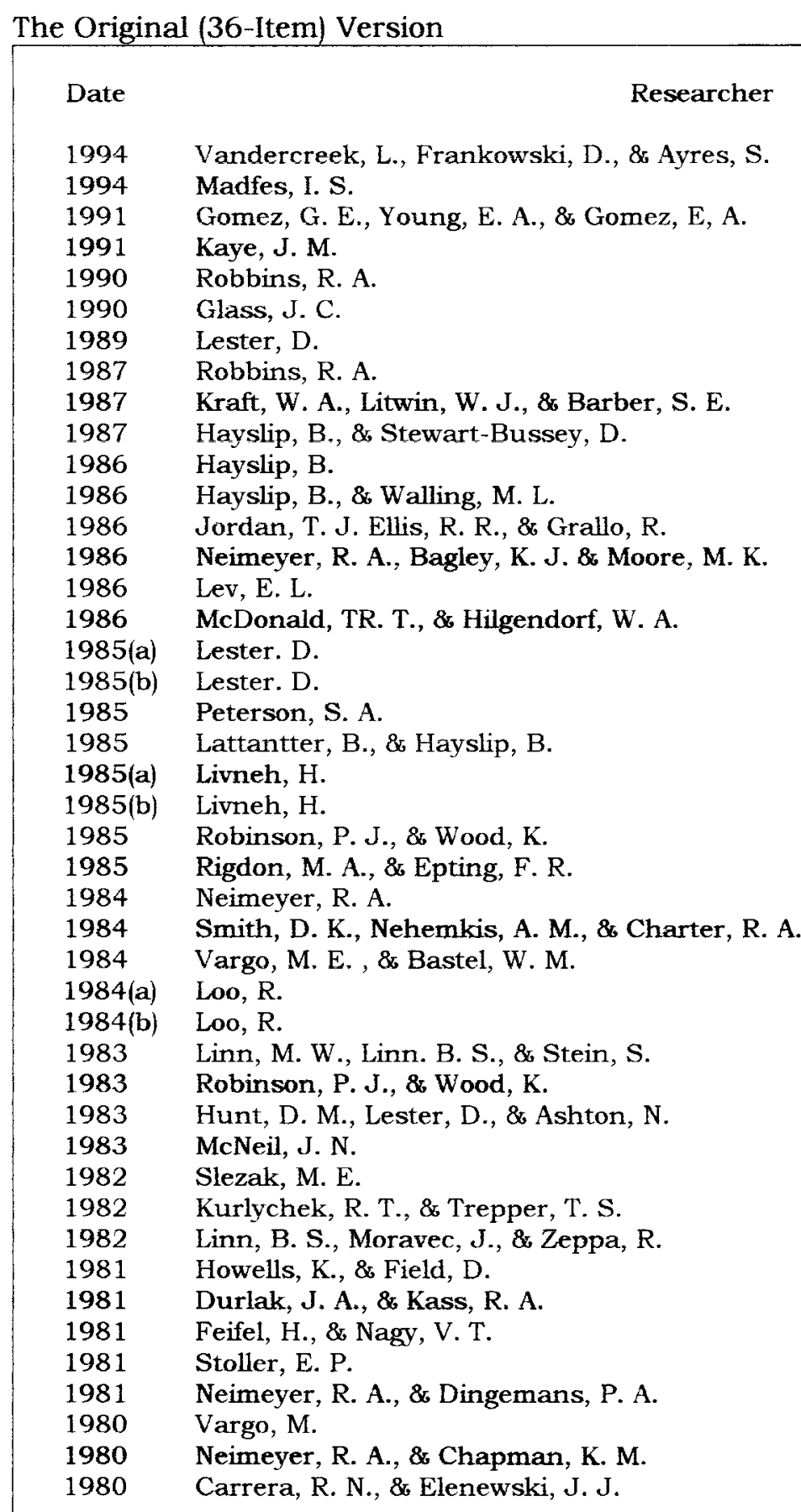


The Original (36 Item) Version (continued)

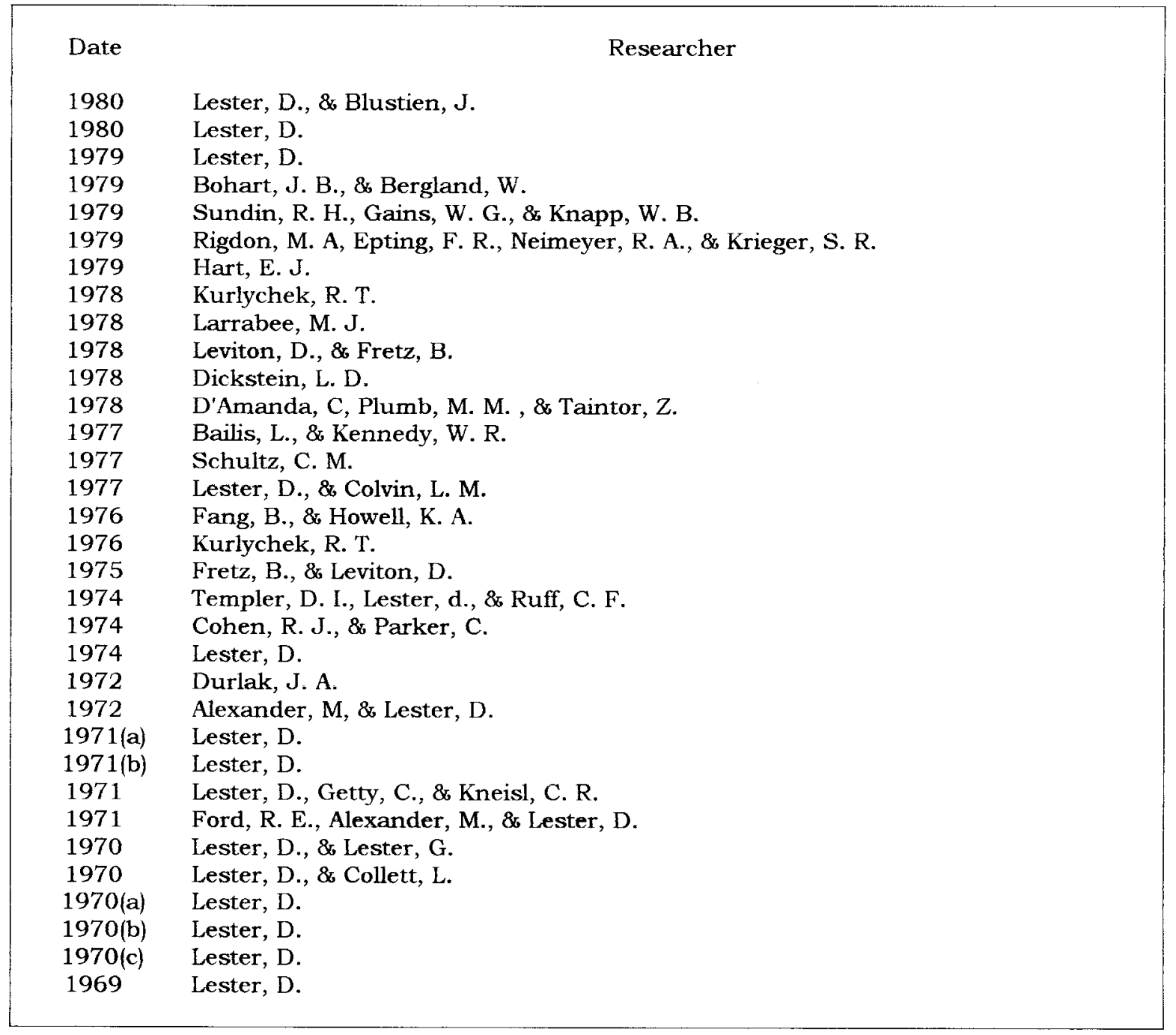

\section{The Revised (32 Item) Version}

Date

Researcher

1998 Kaye, J. M., \& Loscalzo, G.

1997 Kao, S., \& Lusk, B.

1995 Triplett, G. et al

1994 Lan, Y. H.

1994 Kaye, J., Gracely, E., \& Loscalzo, G.

1994 Hayslip, B., Galt, B. A., \& Pinder, M. M.

1993 Lester, D., \& Castromayor, I.

1993 Behrens, T. T.

1992 Chen, J.

1992 Kienow, N. L.

1991 Benvenutti, J. C.

1990 Lester, D. 


\section{Appendix B}

\section{The Multi Dimensional Fear of Death Scale}

Listed below are death-related events and circumstances that some people find to be fear provoking. Indicate the extent to which you agree or disagree with each statement by circling one response for each item. Please do not skip any items.

$$
\begin{gathered}
1=\text { Strongly agree } \quad 2=\text { Mildly agree } 3=\text { Neither agree nor disagree } \\
4=\text { Mildly disagree } 5=\text { Strongly disagree }
\end{gathered}
$$

1. I am afraid of dying very slowly

$\begin{array}{ccccc}1 & 2 & 3 & 4 & 5 \\ 1 & 2 & 3 & 4 & 5 \\ 1 & 2 & 3 & 4 & 5 \\ 1 & 2 & 3 & 4 & 5 \\ 1 & 2 & 3 & 4 & 5 \\ 1 & 2 & 3 & 4 & 5\end{array}$
dead that are really still alive

7. I am afraid of my body being disfigured when I die

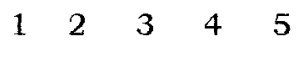

8. I have a fear of not accomplishing my goals in life before dying $\begin{array}{llllll}1 & 2 & 3 & 4 & 5\end{array}$

9. I am afraid of meeting my creator

$\begin{array}{lllll}1 & 2 & 3 & 4 & 5\end{array}$

10. I am afraid of being buried alive

$\begin{array}{lllll}1 & 2 & 3 & 4 & 5\end{array}$

11. I dread the thought of my body being embalmed some day

$\begin{array}{lllll}1 & 2 & 3 & 4 & 5\end{array}$

12. I am afraid I will not live long enough to enjoy my retirement $\begin{array}{llllll}1 & 2 & 3 & 4 & 5\end{array}$

13. I am afraid of dying in a fire

$\begin{array}{lllll}1 & 2 & 3 & 4 & 5\end{array}$

14. Touching a corpse would not bother me.

$\begin{array}{lllll}1 & 2 & 3 & 4 & 5\end{array}$

15. I do not want medical students using my body for

$\begin{array}{lllll}1 & 2 & 3 & 4 & 5\end{array}$ practice after I die

16. If the people I am very close to were to die suddenly, I

$\begin{array}{lllll}1 & 2 & 3 & 4 & 5\end{array}$ would suffer for a long time

17. If I were to die tomorrow, my family would be upset for a long time

18. I am afraid that death is the end of one's existence

$\begin{array}{lllll}1 & 2 & 3 & 4 & 5\end{array}$

19. People should have autopsies to ensure that they are dead

$\begin{array}{lllll}1 & 2 & 3 & 4 & 5\end{array}$

20. The thought of my body being found after I die scares me

$\begin{array}{lllll}1 & 2 & 3 & 4 & 5\end{array}$ 
The Multi Dimensional Fear of Death Scale (continued)

21. I am afraid I will not have time to experience everything $\quad \begin{array}{lllll}1 & 2 & 3 & 4 & 5\end{array}$ I want to do

22. I am afraid of experiencing a great deal of pain when I die $\begin{array}{llllll}1 & 2 & 3 & 4 & 5\end{array}$

23. Discovering a dead body would be a horrifying experience $\begin{array}{llllll}1 & 2 & 3 & 4 & 5\end{array}$

24. I do not like the thought of being cremated $\quad \begin{array}{lllll}1 & 2 & 3 & 4 & 5\end{array}$

25. Since everyone dies, I won't be too upset when my friends die $\begin{array}{llllll}1 & 2 & 3 & 4 & 5\end{array}$.

26. I would be afraid to walk through a graveyard alone, at night $1120 \begin{array}{llll} & 2 & 4 & 5\end{array}$

27. I am afraid of dying of cancer $\quad \begin{array}{lllll}1 & 2 & 3 & 4 & 5\end{array}$

28. It doesn't matter whether I am buried in a wooden box or $\begin{array}{llllll}1 & 2 & 3 & 4 & 5\end{array}$ a steel vault

29. It scares me to think I may be conscious while lying $\quad \begin{array}{lllll}1 & 2 & 3 & 4 & 5\end{array}$ in a morgue

30. I am afraid that there may not be a Supreme Being $\quad \begin{array}{lllll}1 & 2 & 3 & 4 & 5\end{array}$

31. I have a fear of suffocating (including drowning) $\quad \begin{array}{lllll}1 & 2 & 3 & 4 & 5\end{array}$

32. It would bother me to remove a dead animal from the road. $\begin{array}{lllll}1 & 2 & 3 & 4 & 5\end{array}$

33. I do not want to donate my eyes after I die $\quad \begin{array}{lllll}1 & 2 & 3 & 4 & 5\end{array}$

34. I sometimes get upset when acquaintances die. $\quad \begin{array}{lllll}1 & 2 & 3 & 4 & 5\end{array}$

35. The thought of being locked in a coffin after I die scares me $\begin{array}{llllll}1 & 2 & 3 & 4 & 5\end{array}$

36. No one can say, for sure, what will happen after death $\quad \begin{array}{llllll}1 & 2 & 3 & 4 & 5\end{array}$

37. If I die, my friends would be upset for a long time $\quad \begin{array}{lllll}1 & 2 & 3 & 4 & 5\end{array}$

38. I hope more than one doctor examines me before I $\quad \begin{array}{llllll}1 & 2 & 3 & 4 & 5\end{array}$ am pronounced dead

39. I am afraid of things, which have died. $\quad \begin{array}{lllll}1 & 2 & 3 & 4 & 5\end{array}$

40. The thought of my body decaying after I die scares me $\quad \begin{array}{llllll}1 & 2 & 3 & 4 & 5\end{array}$

41. I am afraid I will never see my children grow up $\quad \begin{array}{llllll}1 & 2 & 3 & 4 & 5\end{array}$

42. I have a fear of dying violently $\quad \begin{array}{lllll}1 & 2 & 3 & 4 & 5\end{array}$ 


\section{Appendix C}

\section{The EPI-Short Form}

The following questions ask about how you typically feel and behave. Read each question and then circle the response option (Yes or No) which you think best relates to you. There are no right or wrong answers.

1. Do you sometimes feel happy, sometimes depressed, without Yes No any apparent reason?

Y $\quad \mathrm{N}$

2. Do you usually take the initiative in making new friends?

$\mathrm{Y} \quad \mathrm{N}$

3. I like to gossip at times.

$\mathrm{Y} \quad \mathrm{N}$

4. Do you prefer action to planning for action?

Y N

5. Are you inclined to be quick and sure in your actions?

$\mathrm{Y} \quad \mathrm{N}$

6. There have been occasions when I took advantage of someone. $\quad Y \quad N$

7. Do you have frequent ups and downs in mood, either with or $\quad Y \quad N$ without apparent cause?

8. Are you frequently "lost in thought" even when supposed to be taking part in a conversation?

9. I'm always willing to admit it when I make a mistake. $\quad Y \quad N$

10. Are you happiest when you get involved in some project that $\quad Y \quad N$ calls for rapid action?

11. Would you rate yourself as a lively individual?

$\mathrm{Y} \quad \mathrm{N}$

12. I always try to practice what I preach.

13. Are you inclined to be moody?

14. Are you sometimes bubbling over with energy and sometimes very sluggish?

15. I sometimes try to get even rather than forgive and forget. $\quad Y \quad N$

16. Does your mind often wander while you are trying to concentrate? $Y \quad N$

17. Would you be very unhappy if you were prevented from $\quad$ Y $\quad N$ making numerous social contacts?

18. At times I have really insisted on having things my own way. $\quad Y \quad N$

19. There have been occasions when I felt like smashing things. $\quad Y \quad N$

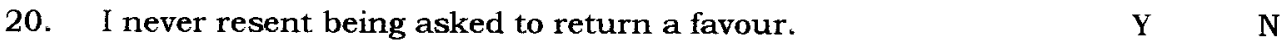

21. I have never been irked when people expressed ideas very $\quad$ Y $\quad N$ different from my own.

22. I have never deliberately said something to hurt someone's feelings. 


\section{Appendix D}

Johns (1993) Model For Structured Reflection

\begin{tabular}{|c|c|c|}
\hline & 1.1 & Describe the experience \\
\hline \multicolumn{3}{|l|}{ 1. Phenomenon } \\
\hline 2. Causal & 2.1 & What essential factors contributed to this experience? \\
\hline 3. Context & 3.1 & $\begin{array}{l}\text { What are the significant background factors to this } \\
\text { experience? }\end{array}$ \\
\hline \multirow[t]{7}{*}{ 4. Reflection } & 4.1 & What was I trying to achieve? \\
\hline & 4.2 & Why did I intervene as I did? \\
\hline & 4.3 & $\begin{array}{l}\text { What were the consequences for myself, the patient and } \\
\text { the people I work with? }\end{array}$ \\
\hline & 4.4 & $\begin{array}{l}\text { How did I feel about this experience when it was } \\
\text { happening? }\end{array}$ \\
\hline & 4.5 & How did the patient feel about it? \\
\hline & 4.6 & How do I know how the patient felt? \\
\hline & 4.7 & What factors influenced my decision? \\
\hline \multirow[t]{2}{*}{ 5.Alternative actions } & 5.1 & What other choices did I have? \\
\hline & 5.2 & What would be the consequences of these other choices? \\
\hline \multirow[t]{3}{*}{ 6. Learning } & 6.1 & How do I feel about this experience? \\
\hline & 6.2 & Could I have dealt better with the experience? \\
\hline & 6.3 & What have I learnt from the experience \\
\hline
\end{tabular}


Appendix E

Permission to Use the Collett-Lester Fear of Death and Dying Scale

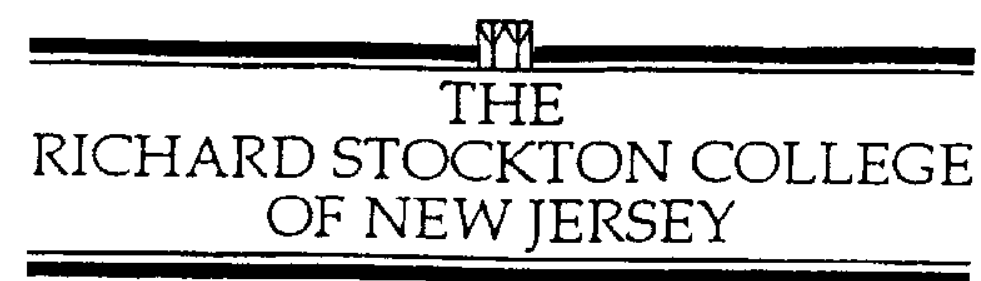

(609) 652-1776

To whom it may concern

April 6, 1999

This is to formally certify that Deborah Mooney has my permission to use the Collett-Lester fear of scale in any way that sine wants -- to make as many copies as needed and to modify it as needed.

David Lester, Ph.D.

Professor of Psychology 